\title{
REVIEW \\ Basolateral amygdala and stress-induced hyperexcitability affect motivated behaviors and addiction
}

\author{
BM Sharp
}

The amygdala integrates and processes incoming information pertinent to reward and to emotions such as fear and anxiety that promote survival by warning of potential danger. Basolateral amygdala (BLA) communicates bi-directionally with brain regions affecting cognition, motivation and stress responses including prefrontal cortex, hippocampus, nucleus accumbens and hindbrain regions that trigger norepinephrine-mediated stress responses. Disruption of intrinsic amygdala and BLA regulatory neurocircuits is often caused by dysfunctional neuroplasticity frequently due to molecular alterations in local GABAergic circuits and principal glutamatergic output neurons. Changes in local regulation of BLA excitability underlie behavioral disturbances characteristic of disorders including post-traumatic stress syndrome (PTSD), autism, attention-deficit hyperactivity disorder (ADHD) and stressinduced relapse to drug use. In this Review, we discuss molecular mechanisms and neural circuits that regulate physiological and stress-induced dysfunction of BLA/amygdala and its principal output neurons. We consider effects of stress on motivated behaviors that depend on BLA; these include drug taking and drug seeking, with emphasis on nicotine-dependent behaviors. Throughout, we take a translational approach by integrating decades of addiction research on animal models and human trials. We show that changes in BLA function identified in animal addiction models illuminate human brain imaging and behavioral studies by more precisely delineating BLA mechanisms. In summary, BLA is required to promote responding for natural reward and respond to second-order drug-conditioned cues; reinstate cue-dependent drug seeking; express stress-enhanced reacquisition of nicotine intake; and drive anxiety and fear. Converging evidence indicates that chronic stress causes BLA principal output neurons to become hyperexcitable.

Translational Psychiatry (2017) 7, e1194; doi:10.1038/tp.2017.161; published online 8 August 2017

\section{INTRODUCTION}

A critical component of the limbic system, the amygdaloid complex, integrates information regarding fear and anxietyinducing stimuli, regulates emotional and behavioral responses, and is involved in reward. Disruption of local GABAergic circuitry regulating the activity of basolateral amygdala (BLA) principal output neurons results in hyperexcitability of these neurons. Hyperactive inputs from these BLA neurons appear to have a significant role in disturbing the regulation of key brain regions (that is, prefrontal cortex, nucleus accumbens and hindbrain) governing cognition, motivation and autonomic responses.

The hyperexcitability of BLA principal neurons is associated with behavioral disorders characterized by excessive fear and anxiety (for review, see Prager et al. ${ }^{1}$ ). Hereditary (for example, autism and attention-deficit hyperactivity disorder, $A \mathrm{AHD}^{2,3}$ ), congenital and acquired abnormalities (for example, addiction) affecting neurodevelopment (for example, $\mathrm{ADHD}^{4}$ ) or causing neurotrauma (for example, post-traumatic stress syndrome) and dysfunctional neuroplasticity (for example, addiction) give rise to these behavioral disorders, which involve the amygdala and BLA. Not only are emotional responses to fear and anxiety-inducing stimuli affected, but disturbances of cognition, motivation and autonomic activity are also part of these behavioral disorders.

The basal and lateral amygdala, designated as the BLA, is one of 13 amygdaloid regions. BLA contains the following three types of cells: (i) most (80-90\%) are glutamatergic pyramidal output neurons (that is, principal neurons), similar to those in neocortex; (ii) subsets of GABAergic interneurons (for reviews, see Capogna $^{5}$ and Pitkanen ${ }^{6}$ ) that frequently coexpress other signature neuropeptides and phenotype-specific enzymes; and (iii) neuroglial cells. These three cell types participate in the local circuits (for example, feed-forward and feedback inhibition) regulating the activity of local GABAergic neurons and the principal output neurons that innervate multiple brain regions involved in the orchestrated somatic and behavioral responses to stressful stimuli. ${ }^{7}$ Primary afferents to BLA are also glutamatergic, prominently from stria terminalis or originating from the lateral amygdala (LA), the primary intra-amygdaloid input to BLA. ${ }^{8}$

This Review will emphasize stress-induced neuroplasticity in BLA control mechanisms that eventuate in dysfunctional and hyperexcitable BLA outputs to nucleus accumbens core (NAcc) and abnormal motivated behavior, exemplified by drug addiction. We begin with coverage of the physiological regulation of BLA by neurotransmitter receptors expressed by interneurons and principal neurons. We then discuss the role of BLA inputs to NAcc in processing affective information involved in the formation of conditioned cues that promote goal-directed behavior. In the third section, we review the effects of acute and chronic stress on the induction of neuroplasticity involving receptor expression, signaling and electrophysiological responses of BLA neurons and intrinsic neural circuits. We also discuss stress-induced alterations in the activity of afferent dopaminergic, noradrenergic and glutamatergic inputs to BLA and synaptic responses. The behavioral consequences of these changes in afferent inputs

Department of Pharmacology, College of Medicine, University of Tennessee Health Science Center, Memphis, TN, USA. Correspondence: Dr BM Sharp, Department of Pharmacology, College of Medicine, University of Tennessee Health Science Center, 19S. Manassas, CRB \#220, Memphis, TN 38103, USA.

E-mail: bsharp@uthsc.edu

Received 17 January 2017; revised 16 May 2017; accepted 8 June 2017 
and intrinsic BLA neuron function are discussed in several illustrative models, both animal and human. In section four, the effects of stress on motivation, reward and drug-related behaviors that depend on BLA and neural connections between BLA and NAcc are reviewed. Lastly, section five integrates insights gleaned from human brain imaging studies of regional reactivity to the presentation of salient drug cues with results from animal models of circuit neuroplasticity.

\section{SECTION 1. REGULATION OF BLA NEURONS AND CIRCUITRY THAT PROCESS INFORMATION DIRECTLY AFFECTING EMOTION AND MOTIVATION}

Hyperexcitability and GABAergic control mechanisms

Pathological disruption of GABAergic control mechanisms causes hyperexcitability of the amygdala that has a key role in anxiety, dysfunctional regulation of emotional responsiveness and excessive vigilance. ${ }^{1,9,10}$ Anxiety due to hyperexcitability of the amygdala and BLA is present in animal models and humans affected by neuropsychiatric, neurodevelopmental and neurodegenerative disorders. These include post-traumatic stress disorder $\left(\mathrm{PTSD}^{11}\right)$, autism/fragile $X$ syndrome ${ }^{12}$ and Alzheimer's disease. ${ }^{13}$

PTSD, in particular, develops after repeated exposure to environments that engender intense responses to stress and fear-inducing stimuli. Targeted lesion of a very small subset of rat BLA GABA interneurons, coexpressing neurokinin ${ }_{1 r}$ and somatostatin (3\% of total GABA interneurons), appears to be sufficient to impair the feedforward inhibition of BLA principal output neurons-resulting in enhanced neuronal activity and anxiety behaviors. ${ }^{11}$ In contrast, animals with greater numbers of BLA GABA interneurons are relatively resistant to stimuli for unconditioned fear. ${ }^{14}$ In both human and animal studies, traumatic stress alters the expression of $G_{A B A}-R$ subunits. ${ }^{15-17}$ Polymorphisms in the $a_{2}$ subunit of $G A B A_{A}-R$ predispose to PTSD, implicating genetic variation as a factor in the vulnerability to stressors. Hence, the pivotal interaction of gene $x$ environment (for example, traumatic exposure in childhood) determines the outcome of traumatic stress in adults. ${ }^{18}$

Additional subsets of BLA GABA interneurons, such as those positive for somatostatin and parvalbumin (PV), selectively mediate the acquisition of fear conditioning. The learned association of footshock with auditory cues alters the inhibitory function of these GABA interneurons, thereby disinhibiting glutamatergic principal neurons that project to multiple brain regions. ${ }^{19}$ Pharmacological studies have shown that activation or inhibition of $G_{A B A}-R$ mediates anxiolytic or anxiogenic behavioral responses, respectively, ${ }^{20}$ and enhanced expression of BLA $a_{2}$ subunit-containing $G A B A_{A}-R$ has been associated with increased anxiety in rats identified by selection, using contextual fear conditioning. ${ }^{21}$ Lastly, repeatedly stressed rats show deficient norepinephrine-induced GABAergic neurotransmission in BLA due to impaired presynaptic $a_{1 A}$ adrenoreceptors. ${ }^{22}$ Thus, by regulating the excitability of principal neurons, the GABAergic interneuronal network within the amygdala and BLA determines behavioral responsiveness to external stimuli that induce anxiety and fear. Pathological alterations of function within this GABAergic network, induced by stimuli that cause severe stress and fear or tissue damage (for example, traumatic brain injury), appear to be sufficient to cause increased excitability of BLA principal neurons - eventuating in disabling behavioral disorders such as PTSD and generalized anxiety. ${ }^{23}$

\section{Hyperexcitability and neuroplasticity}

Altered excitability of BLA principal projection neurons can also reflect intrinsic changes in these neurons or in non-GABAergic inputs that modulate the excitability of principal neurons. Synaptic processes that depend on altered expression and function of neurotropins, synaptic receptors and neuronal signaling may modify excitability. In addition, the intrinsic membrane excitability of principal neurons may be affected.

Amygdaloid brain-derived neurotropic factor (BDNF), necessary for synaptic neuroplasticity, is required for memory consolidation of fear conditioning and extinction. ${ }^{24} \mathrm{~A}$ single-nucleotide polymorphism in the BDNF gene (Val66Met) has been shown to modify the stability and activity-dependent secretion of BDNF and to cause dysfunctional BDNF signaling in humans. ${ }^{25}$ Consequently, both amygdala-dependent fear conditioning and fearextinction learning are modulated by this and similar BDNF polymorphisms. ${ }^{26}$ BDNF also modulates the generalization of fear responses and may be associated with increased stress-induced anxiety. ${ }^{27}$ Altered glutamatergic synaptic function in the centromedial amygdala (CEm) of mice with BDNF (Val66Met), which mediates abnormal fear conditioning and extinction, might involve dysfunction of glutamatergic projections from BLA to CEm neurons. $^{28}$

Afterhyperpolarization (AHP) of the neuronal membrane is an integral mechanism controlling neuronal excitability. Intrinsic excitability of BLA principal neurons is modulated by norepinephrine and chronic exposure to stress, which activate $\beta$ adrenergic receptors expressed on these neurons. ${ }^{29}$ Intraneuronal trafficking of calcium-activated potassium channels (that is, SK) that control the medium component of the AHP is modulated by $\beta$-adrenergic receptors. Reduction of SK channel activity decreases AHP and augments neuronal firing in dorsal striatum; ${ }^{30}$ similar mechanisms operate in BLA (see Section 3). Thus, stress and norepinephrine affect neuronal firing acutely by activating $\beta$ adrenergic receptors and, on a more extended basis, by altering the membrane AHP.

BLA neural network: feed-forward and feedback interactions between BLA GABA interneurons and principal output neurons Cortical and subcortical regions innervate BLA. The excitability of BLA principal glutamatergic neurons is regulated by specific subsets of BLA GABA interneurons. ${ }^{31}$ Calbindin-immunopositive GABA interneurons, activated by glutmatergic cortical inputs, induce feed-forward inhibition through synaptic contact with the dendrites of principal neurons. ${ }^{32}$ PV-immunopositive BLA GABA interneurons ( $40 \%$ of BLA GABA interneurons) innervate the soma of principal neurons and appear to mediate feedback inhibition. ${ }^{5,31}$ Strong local inputs from principal neurons to $\mathrm{PV}^{+}$ interneurons appear to induce this feedback inhibition. ${ }^{33}$ Postsynaptically, principal neurons express primarily a2 subunitcontaining $G A B A_{A}-R$, whereas extrasynaptic $G A B A_{A}-R$, mediating tonic GABAergic currents, are primarily assembled by principal neurons from a5 subunits. ${ }^{34}$ These networks of GABA interneurons control excitability of the BLA by regulating the resting firing rate of principal neurons. ${ }^{8,35}$ Disrupted GABAergic regulation reduces inhibitory inputs and usually produces hyperexcitability of BLA principal neurons that contributes to emotional lability, anxiety and disrupted motivation. ${ }^{1,36}$

\section{Membrane receptors modulating the activity of BLA GABA} interneurons

Projections from multiple cortical and subcortical regions (see Figure 1) modulate the activity of a wide range of receptors throughout BLA (see Table 1) including the cannabinoid (CB1), aminergic (for example, dopaminergic: DA-R), serotoninergic (for example, $5 \mathrm{HT}_{1 \mathrm{~A}}$ ), nicotinic cholinergic (nAChR), GABAergic (for example, $G A B A_{B}$ ) and glutamatergic receptors (for example, GluK1) expressed by BLA GABA interneurons. The following receptors inhibit local GABA release through multiple presynaptic signaling molecules: CB1, located on cholecystokininimmunopositive GABA interneurons that modulate the activity of principal output neurons; ${ }^{37} 5 \mathrm{HT}_{1 \mathrm{~A}} ;{ }^{38}$ metabotropic $\mathrm{GABA}_{\mathrm{B}}$, which are primarily located on BLA GABA interneurons; ${ }^{39}$ and D2R. 
Dense dopaminergic projections from ventral tegmental area $(\mathrm{VTA})^{40}$ and substantia nigra innervate GABA interneurons, coexpressing $\mathrm{PV}^{41}$ and $\mathrm{D} 2 \mathrm{R}$, and suppress GABA release. ${ }^{42}$ In addition, suppression of the feed-forward inhibition of principal neurons by GABA interneurons is mediated by D2R. ${ }^{43}$ In contrast, activation of D1R on BLA projection neurons increases excitability and firing. ${ }^{44,45}$ The net effect of increased dopaminergic input to BLA appears to be increased BLA neural activity.

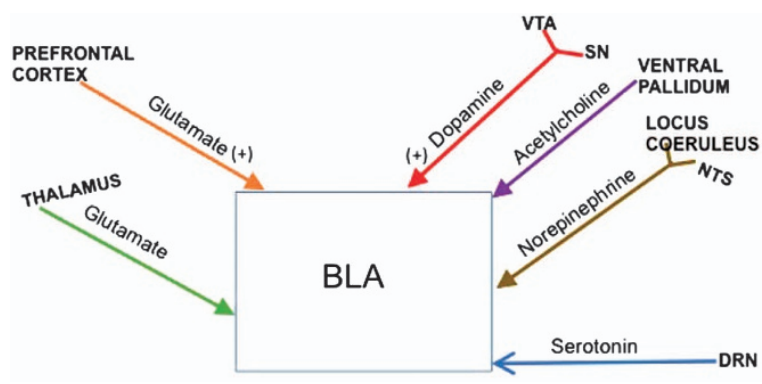

Figure 1. Schematic representation of neural projections from multiple brain regions to basolateral amygdala (BLA). The primary neurotransmitters are identified. DRN, dorsal raphe nucleus; NTS, nucleus tractus solitarius; SN, substantia nigra; VTA, ventral tegmental area.
In contrast to presynaptic inhibition of GABA release, several presynaptic receptors on GABA interneurons, such as adrenergic receptors (that is, a1 A, a2), enhance GABA release. ${ }^{22,46}$ In addition, kainate receptors increase BLA excitatory synaptic activity by modulating the release of both GABA and glutamate within BLA. ${ }^{47}$ nAChRs, ${ }^{48}$ both homomeric $a_{7}$ and heteromeric $a_{4} \beta_{2},{ }^{49,50}$ regulate the BLA neural network. nAChRs, particularly $a_{7}$, enhance both excitatory and inhibitory synaptic activity, yet a net decrease in BLA activity has been observed. ${ }^{50}$ An overall decrease in BLA activity is also observed after optogenetic stimulation of basal forebrain inputs to BLA, which activate both nicotinic and muscarinic receptors. This decrease in BLA activity appears to depend on the activation state of neuronal circuits within BLArequiring inactive principal neurons. ${ }^{32}$

Postsynaptic receptors for glutamate, GABA, serotonin and other neurotransmitters also modulate the activity of GABA interneurons. Both a-amino-3-hydroxy-5-methyl-4-isoxazolepropionic acid receptors (AMPAR) and $\mathrm{N}$-methyl-D-aspartate receptors (NMDAR), containing a heterogeneous population of subunits, are expressed postsynaptically on BLA GABA interneurons. ${ }^{51}$ Longterm potentiation of GABA interneurons is mediated by AMPAR lacking GluR2 subunits. ${ }^{52}$ These interneurons, which appear to be part of the calbindin-immunopositive subset, provide feedforward inhibition of BLA principal neurons ${ }^{53}$ (see Figure 2). Post-synaptic $5 \mathrm{HT}_{2}$, expressed on $\mathrm{PV}^{+} \mathrm{GABA}$ interneurons,

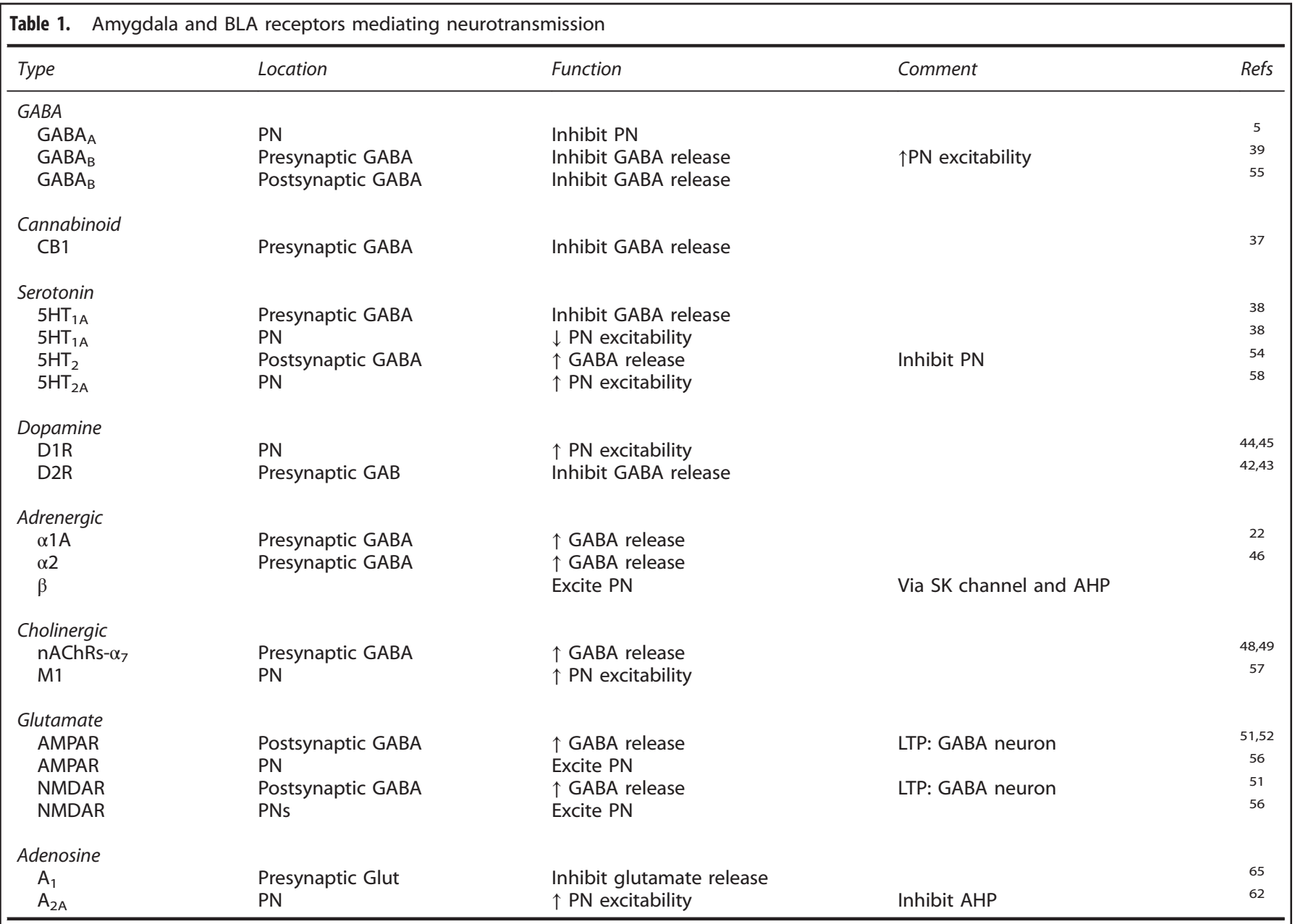

Abbreviations: AHP, afterhyperpolarization; AMPAR, $\alpha$-amino-3-hydroxy-5-methyl-4-isoxazolepropionic acid receptor; BLS, basolateral amygdala; LTP, long-term potentiation; $\mathrm{nAChR}$, nicotinic cholinergic receptor; NMDAR, N-methyl-D-aspartate receptor; PN, principal neuron. 


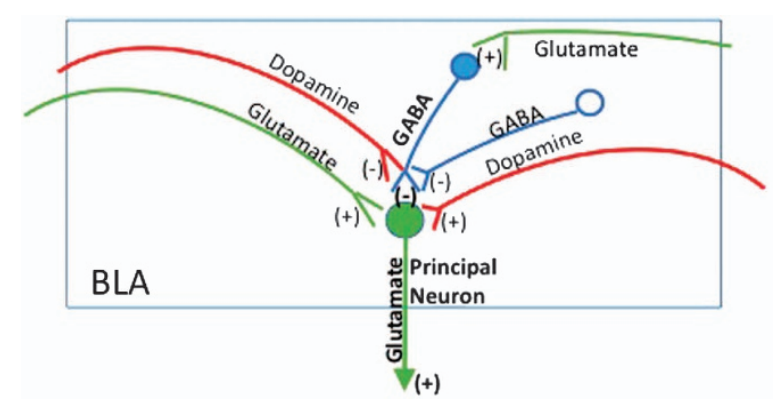

Figure 2. Schematic representation of GABA, glutamate and dopamine neural inputs to a GABA interneuron (solid blue) regulating a basolateral amygdala (BLA) principal neuron (solid green) and directly to the principal neuron. The pre- and postsynaptic excitatory (+) and inhibitory (-) effects of each neurotransmitter are shown, as are the glutamate and dopamine projections to BLA.

enhances excitability and GABA release, suppressing the activity of principal neurons. ${ }^{54}$ Lastly, postsynaptic $G_{A B A}$ receptors hyperpolarize a wide variety of GABA interneurons. ${ }^{55}$

Membrane receptors modulating activity of BLA principal neurons In addition to the regulation of principal glutamatergic neurons by local GABAergic feed-forward and feedback, multiple receptor systems (see Table 1) located on the postsynaptic membrane of principal glutamatergic neurons modulate their intrinsic excitability. Glutamatergic inputs activate principal neurons through both fast AMPAR and slower NMDAR. ${ }^{56}$ M1 muscarinic receptors, predominant among the multiple muscarinic subtypes present in amygdala, also increase the excitability of principal neurons. ${ }^{57}$ In addition, $5 \mathrm{HT}_{2 \mathrm{~A}}$ enhances excitability by increasing intracellular calcium, ${ }^{58}$ whereas $5 \mathrm{HT}_{1 \mathrm{~A}}$ diminishes excitability by hyperpolarization. ${ }^{38}$ Adenosine $A_{2 A}$ receptors, expressed in BLA at relatively high levels, ${ }^{59}$ are $\mathrm{G}_{\mathrm{s}}$-coupled, ${ }^{60}$ thereby enhancing cAMP signaling. $\mathrm{G}_{\mathrm{s}}$-coupled receptors, in amygdala and other brain regions, increase neuron excitability and the probability of firing by reducing membrane AHP. ${ }^{29,61}$ Similarly, $A_{2 A}$ receptors appear to increase the intrinsic excitability of BLA principal neurons by inhibition of $\mathrm{AHP}^{62}$ - a mechanism that is also affected by stressors. ${ }^{63,64}$ In contrast to the excitatory effects of $A_{2 A}$ receptors, adenosine $A_{1}$ receptors expressed on presynaptic glutamatergic cortical inputs to BLA principal neurons reduce excitation by inhibiting glutamate release. ${ }^{65}$ Lastly, dopaminergic projections from VTA and substantia nigra innervate BLA principal neurons. ${ }^{45}$ D1R activation decreases slowly inactivating K1 currents, thereby increasing excitability and firing of principal neurons. In contrast, activated D2R increase input resistance. ${ }^{44,66}$

In summary, BLA inputs from multiple brain regions modulate the activity of principal output neurons through direct effects on subtype-specific receptors expressed by these neurons and GABA interneurons. Local circuits regulate principal neurons through feed-forward and feedback mechanisms. Both impaired GABA regulation, which disinhibits principal neurons, and altered intrinsic membrane properties (for example, AHP) of principal neurons cause hyperexcitability of these neurons.

\section{SECTION 2. BLA INPUTS TO NACC: ROLE IN PROCESSING AFFECTIVE INFORMATION INVOLVED IN FORMATION OF CONDITIONED CUES THAT PROMOTE GOAL-DIRECTED BEHAVIOR}

Neuroanatomy

NAcc medium spiny neurons are innervated by glutamatergic inputs from several regions including BLA and by VTA dopaminergic inputs. ${ }^{7,67,68}$ From BLA, monosynaptic glutamatergic projections converge on to NAcc distal dendrites and spines, ${ }^{69}$ whereas VTA efferents release both synaptic and extrasynaptic DA, diffusely affecting neural circuits. ${ }^{70,71}$

\section{Animal studies of electrophysiology}

A complex interaction between BLA glutamatergic and VTA dopaminergic inputs to NAcc is required for goal-directed behaviors that depend on BLA-NAcc neural connections. The critical function of BLA in triggering goal-directed behavior is evident in that BLA neuronal responses to cues precede the activation of NAcc neurons and cue-evoked excitation of NAcc requires input from BLA. High-frequency activity of these BLA projections stimulates increased NAcc activity that involves modulation by activated D1R on medium spiny neurons. ${ }^{72-75}$ BLA electrical stimulation also appears to directly induce NAcc DA release through NMDA receptor-dependent mechanisms, independent of effects on VTA dopaminergic cell bodies. ${ }^{76}$

\section{Animal studies of behavior}

BLA is involved in associative learning in which conditioned appetitive cues engender goal-directed behavior. ${ }^{77-81}$ In coordination with DA inputs to nucleus accumbens (NAc; the rewardresponsive interface connecting limbic and motor systems), BLA interactions with NAc promote reward-seeking behaviors. Conditioned cues that predict reward utilize neural circuitry connecting $\mathrm{BLA}$ and $\mathrm{NAc}{ }^{69,79,82}$ to modulate the goal-directed behavior manifest by a set of motoric behavioral responses. These excitatory connections are necessary for cocaine-seeking behavior in rats under a second-order schedule; ${ }^{82}$ optogenetic experiments demonstrate that they also facilitate, but are not required for acquisition of motivated sucrose seeking in conjunction with Da inputs to NAc. ${ }^{79}$ Chemical disconnection of BLA from NAc disrupts appetitive second-order conditioned responses, which depend on a secondary cue associated with the primary conditioned cue. Therefore, BLA positively modulates primary conditioned responses and is required for second-order responses. In addition, BLA is required for cue-induced reinstatement of extinguished cocaine-seeking behavior and for chronic stress-enhanced reacquisition of nicotine taking (discussed in Section 4).

Monosynaptic glutamate projections from BLA mediate affective inputs to NAc. ${ }^{83,84}$ BLA inputs to NAcc positively regulate unconditioned D1R-induced hyperlocomotion, and may exert a tonic facilitative effect on D1R-dependent locomotion. ${ }^{72,85}$ In contrast, prefrontal cortical (PFC) glutamate inputs to NAcC tonically inhibit D2R-driven locomotion. ${ }^{85}$ From the perspective of decision-making, the difference in the locomotive effects of these two input circuits might reflect neural systems that result in impulsive, goal-oriented behavioral responses to rewards versus deliberate responses based on anticipating behavioral consequences and inhibiting undesired movements (see Noel et al. ${ }^{86}$ ).

In a discrimination task, the reward-seeking behavioral response to incentive cues depends on the integration of information from both VTA dopaminergic and BLA glutamatergic inputs to NAc. ${ }^{87}$ In $B L A$, the discriminative stimulus but not the neutral stimulus evoked a late phase of prolonged neuronal firing, perhaps encoding the incentive value of the cue, and the latency to excitation was shorter than that in NAc. In addition, unilateral inactivation of BLA reduced discriminative stimulus-induced excitation of NAc neurons without affecting behavioral responses. These findings indicate that excitatory BLA inputs drive NAC and transmit information about conditioned appetitive cues that is critical to behavioral responding to predictive cues. Other investigators, studying primates in some experiments, have reported that BLA encodes information about the value of stimuli that predict reward. ${ }^{88,89}$ 
Table 2. Stress-induced neuroplasticity in BLA and amygdala (AMYG)

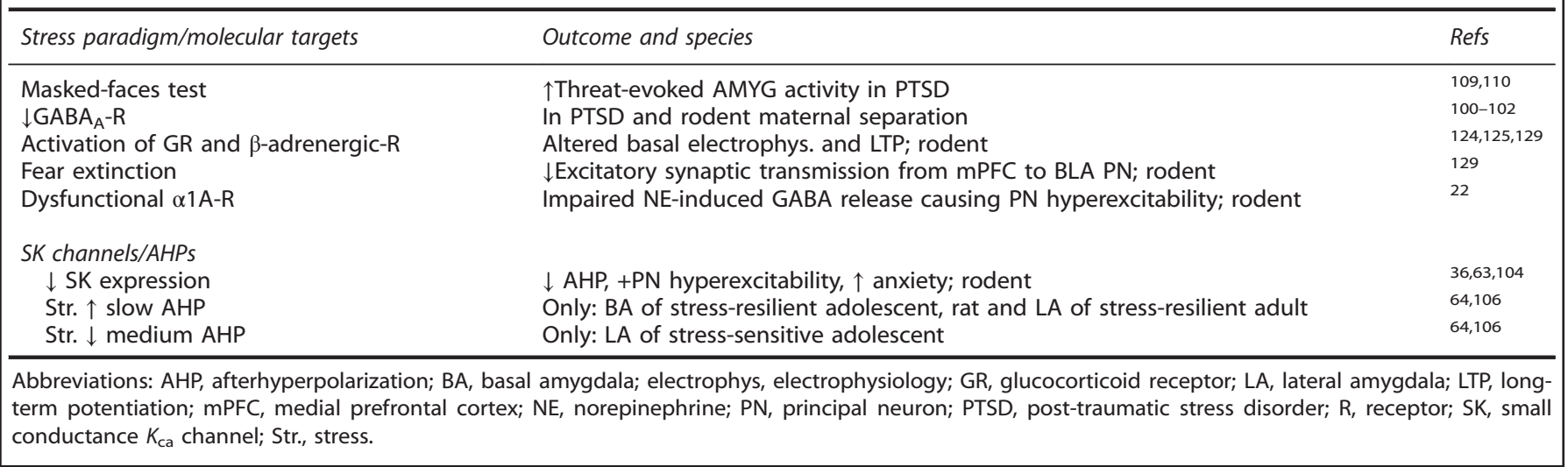

Although the mechanisms controlling both the integration of DA and glutamate inputs by intrinsic NAc circuitry and the behavioral consequences of this integration are not fully elaborated, much is known. Although Da alone will not trigger firing of NAc neurons, the release of Da from VTA projections to NAc in response to conditioned cues is required to maintain or restore incentive cue-dependent firing of NAc neurons in face of tasks requiring high effort or flexibility in sustaining behavioral responses. ${ }^{90,91}$ The release of Da in NAc also appears to maintain engagement or facilitate re-engagement in reward-seeking behavior, particularly if cue presentation is unpredictable. ${ }^{92}$

\section{SECTION 3. BLA AND AMYGDALA RESPONSES TO STRESS: NEUROPLASTICITY INVOLVING RECEPTOR EXPRESSION, SIGNALING AND ELECTROPHYSIOLOGICAL RESPONSES}

Intrinsic changes in BLA neurons and circuits in animals and humans

In $\mathrm{BLA}$, enhanced expression of $a_{2}$ subunit-containing $G_{A B A}-R$ has been associated with increased anxiety in rats identified by behavioral selection using contextual fear conditioning. ${ }^{21,93}$ These studies strongly suggest a hereditary basis for variable expression of $B L A a_{2}$ subunit-containing $G A B A_{A}-R$ that directly correlates with the anxiogenic outcome of contextual fear conditioning.

Stress and norepinephrine modulate the activity of BLA interneurons (Table 2). The amygdala is densely innervated by noradrenergic afferents from locus coeruleus and the nucleus of the solitary tract. ${ }^{2,94}$ In rat BLA, footshock stress stimulates release of norepinephrine, which in turn facilitates GABA release. ${ }^{95}$ Norepinephrine activates a1A adrenergic receptors, inducing quantal GABA release by spontaneous, evoked and action potential-independent mechanisms. ${ }^{22}$ On the basis of electrophysiological properties, a subset of BLA GABA interneurons respond to norepinephrine, which may mediate the effects of local GABA interneurons on the memory of passive inhibitory avoidance. ${ }^{96,97}$ Lastly, tailshock stress severely compromised the a1A receptor-dependent release of BLA GABA, potentially contributing to the hyperexcitability of BLA output neuron mechanisms. $^{22}$ Studies have also evaluated the effects of restraint stress on the mRNA encoding a1 adrenergic receptors, although limited to hypothalamus and midbrain. While a single stress session increased mRNA levels in midbrain but not hypothalamus, repeated stress reduced levels in both midbrain and hypothalamus. ${ }^{98}$

Stress affects benzodiazepine binding to $G A B A_{A}-R$ in rodent and human amygdala. Studies in mice acutely exposed to social defeat stress detected a transient increase in benzodiazepine receptor binding within 20 min of stress. ${ }^{99}$ In contrast, positron emission tomography (using $\left[{ }^{11} \mathrm{C}\right]$-flumazenil) of individuals with combat- related PTSD detected a reduction in benzodiazepine binding within PFC and amygdala. ${ }^{100,101}$ In addition, maternal separation without handling of rat pups from birth until postnatal day 14 caused a reduction in benzodiazepine receptors within central and lateral amygdaloid nuclei and in $\gamma 2$ subunits of the GABA receptor, which confer high-affinity benzodiazepine binding. ${ }^{102}$ These studies in rodent and human demonstrate consistent reductions in benzodiazepine binding to $\mathrm{GABA}_{\mathrm{A}}$ receptors induced by chronic stress within PFC and amygdala. To the extent that these findings are applicable to BLA, loss of these $G_{A B A_{A}}$ receptors is likely to alter the excitability of the GABA interneuron network and the regulation of principal output neurons.

Stress affects the expression of small conductance $K_{\text {ca }}$ channels (SK) by BLA principal neurons. In a rodent model of chronic adolescent stress, the social isolation of solitary housing throughout adolescence and into adulthood induces hyperexcitability of BLA principal neurons and increases anxiety-like behaviors in adult rats. ${ }^{63}$ The calcium-activated potassium $\left(K_{\text {ca }}\right)$ channel activity responsible for the medium component of membrane AHP is reduced, accounting for the neuronal hyperexcitability. Reduced BLA expression of the small conductance $K_{\mathrm{ca}}$ channel (SK) is observed, and a positive modulator of this channel restores normal firing of principal neurons in vitro. Intra-BLA administration of this positive SK channel modulator also reduces anxiety behaviors. A similar channelopathy is involved in the hyperexcitability of pyramidal neurons within the LA of rats chronically exposed to stress. Thus, chronic stress-induced neuroplasticity specifically alters the molecular expression of SK channels and the electrophysiological responsiveness of BLA principal neurons, resulting in reversible anxiety-like behavior. The disruption of functional SK channels that dysregulates neuronal activity is also involved in the neurobiological response to stressors such as fear conditioning. ${ }^{103,104}$

Stress-responsive versus stress non-responsive rats show differential sensitivity to the effects of stress on amygdaloid afterhypolarization. The membrane properties of projection neurons within both LA and basal amygdala (BA) were analyzed in stress-vulnerable and stress-resilient adolescent and adult rats exposed to chronic restraint stress. ${ }^{64}$ Stress-vulnerable rats are characterized by heavier adrenal glands, lower body weights and less time in the open arm of an elevated plus maze after chronic restraint. Chronic stress enhances membrane excitability in both amygdaloid regions of adolescent rats. However, BA excitability differs between the stress-vulnerable versus resilient rats in that the slow AHP (sAHP) is greater in the stress-resilient than in stressvulnerable and non-stressed controls, whereas the medium AHP is unaffected. In contrast, the medium AHP in LA neurons, and not the SAHP, is greater in stress-resilient and non-stressed controls than in vulnerable adolescent rats. In adult rats, the SAHP of LA is 
greater in stress-resilient and non-stressed controls than in the stress-vulnerable, and only the LA neurons of stress-vulnerable rats are hyperexcitable. Thus, the effects of chronic stress on membrane AHPs and the resultant neuronal hyperexcitability depend on predisposing vulnerability or resistance to stress: stress reduces LA neuron AHPs in both stress-vulnerable adolescent (that is, medium AHP) and adult (that is, SAHP) rats, whereas stress increases AHPs only in BA neurons (that is, sAHPs) of stressresilient adolescents. Therefore, stress only induces LA neuronal hyperexcitability, thereby promoting anxiety, by reducing SAHP or medium AHP in animals that are sensitive to stress; conversely, stress only reduces the excitability of BA neurons, which protects against anxiety, in animals that are stress-resilient.

The differential sensitivity to stress exhibited by inbred rodent strains, such as BalbC versus C57BL6/J mice, demonstrates the heritability of stress-responsive phenotypes. ${ }^{105,106}$ These two strains differ in multiple behavioral and physiological phenotypes including susceptibility to social defeat stress and anxiety behaviors. At the cellular level, polymorphisms and differences in stress-induced expression of BDNF within certain brain regions (for example, NAc) are associated with the development of behavioral phenotypes characteristic of susceptibility versus resistance to chronic stress. ${ }^{107}$ On the basis of studies such as these in inbred mice, it is plausible to postulate that differences in BLA electrophysiological responses to chronic stress, observed in stress-vulnerable versus stress-resilient males from an outbred rat strain (that is, Sprague-Dawley), are due to genetic and epigenetic variation between individual rats.

In addition to the foregoing effects of stress on BLA and amydaloid function, human studies detect abnormal activity in the amygdala of veterans with PTSD. In a controlled clinical experiment, veterans challenged by the threatening presentation of fearful facial images manifest exaggerated amygdaloid responses. ${ }^{108}$ This study used a masked-faces paradigm that emphasizes intrinsic amygdaloid responses. ${ }^{109,110}$ In comparison with veterans without PTSD, the exaggerated responses, shown by functional magnetic resonance imaging (fMRI), were only evoked by general threat-related stimuli in individuals with PTSD. Thus, intrinsic amygdaloid function demonstrates long-term stressinduced neuroplasticity in individuals with PTSD. Other studies posit additional deficits in the top-down regulation of the amygdala by specific regions of the PFC and other cortical areas (for review, see Rauch et al. ${ }^{111}$ ). Experimental animal models have emphasized the roles of amygdaloid BDNF-tyrosine kinase B, GABAergic and glutamatergic circuitry in abnormal fear conditioning and PTSD (for review, see Mahan and Ressler ${ }^{112}$ ).

Stress-induced alterations in the activity of afferent inputs to rodent BLA and synaptic responses

Increased DA release by stressful stimuli affects BLA interneurons and principal neurons. BLA and amygdala, in general, have a moderate level of dopaminergic innervation from the VTA. However, dopaminergic fibers densely innervate and modulate the activity of principle output neurons and PV-positive GABA interneurons of $B L A .{ }^{45,113}$ The net effect of increased DA input is enhanced BLA activity mediated by the D2R-dependent reduction in GABAergic inhibition of principal output neurons along with D1R-driven excitation of these neurons ${ }^{42-44}$ (see Figure 2). Amygdaloid DA levels are highly responsive to stress ${ }^{114}$ and to the presentation of predictive cues such as those associated with fear-inducing stimuli. ${ }^{115,116}$ In BLA, DA levels increase during both discrimination learning and acute stress from footshock and handling. ${ }^{117,118}$ Both systemic and direct administration of dopaminergic agonists (especially D1R/D5 R) facilitate amygdaladependent behaviors, revealing a critical role for D1R/D5R in the expression of conditioned contextual fear. ${ }^{116,119-121}$ Lastly, activation of amygdaloid D3R is also reported to enhance stimulus-reward learning. ${ }^{122}$

Stress-induced norepinephrine release in BLA and elevation of plasma glucocorticoid facilitate electrophysiological changes in BLA. In previous sections, we reviewed the effects of chronic stress on SK channel expression by BLA principal neurons and presynaptic $a_{1 A}$ adrenoreceptor expression on BLA GABA interneurons. ${ }^{22,29,46,123}$ Stress also modulates the induction of LTP in BLA. ${ }^{124,125}$ Acute restraint stress $(20 \mathrm{~min})$, mild footshock stress and initial exposure to nicotine all stimulate the hypothalamopituitary-adrenal axis ${ }^{126}$ and noradrenergic neurons in locus coeruleus and nucleus tractus solitarius, ${ }^{127}$ increasing the activation of BLA glucocorticoid and $\beta$-adrenergic receptors and, thereby, facilitating induction of LTP in vitro. ${ }^{124}$ However, another study found that elevated-platform stress enhances baseline electrophysiological responses in BLA and inhibits LTP induction in vivo, whereas administration of corticosterone has no affect on LTP. ${ }^{125}$

The effects of stress on BLA electrophysiology appear to be specific to the stress protocol, in part due to the initial activation of different brain regions by levels of physical versus psychogenic stimuli that are unique to each paradigm. ${ }^{128}$ Prolonged stress-induced neuroplasticity manifested by LTP, alterations in baseline electrophysiology and altered expression of SK channels and adrenoreceptors, may have a role in the consolidation of emotional memories by the BLA.

\section{SECTION 4. EFFECTS OF STRESS ON MOTIVATION, REWARD AND DRUG-RELATED BEHAVIORS THAT DEPEND ON BLA, AMYGDALA AND NEURAL CONNECTIONS BETWEEN BLA AND NACC}

Introduction: stress can shift goal-directed behavior to habitual behavior or enhance the motivation for reward

Rodent studies have identified two neural systems corresponding to two types of learning that control instrumental behaviors: goaldirected versus stimulus-response habitual learning (for review, see Balleine and colleagues ${ }^{129,130}$ ). In brief, in the acquisition and expression of goal-directed learning, which involves several regions (for example, insular cortex, prelimbic cortex and dorsomedial striatum), the reward acquires incentive value that establishes an association between an action and an outcome, whereas stimulus-response conditioning, which involves the prelimbic PFC and dorsolateral striatum, establishes only the contingency between response behavior and reward. Using habit strategies, which no longer involve evaluating the consequences of action, behavior is insensitive to a change in the value of the reward. In contrast, in incentive learning, behavior is sensitive to the value of the reward (Table 3 ).

Stress, both acute and chronic, modulates interactions between incentive and habitual learning involved in instrumental behaviors. Human clinical experiments show that stress (that is, socially evaluated cold pressor) prior to instrumental training causes subjects to become insensitive to the devaluation of food reward. ${ }^{131}$ Animal research further establishes that exposure to chronic stress prior to prolonged training causes frontostriatal reorganization (that is, atrophy of medial PFC, hypertrophy of dorsolateral striatum) that is associated with behavioral insensitivity to changes in the value of outcomes. ${ }^{132}$ Thus, prior stress can promote the shift to habitual behaviors at the expense of goaldirected action. This stress-induced behavioral shift is mimicked by co-administration of GRs and yohimbine, which enhance activity of the noradrenergic system. As both agents are necessary for mimicry, administration of a $\beta$-adrenergic antagonist prior to stress is sufficient to prevent the shift from goal-directed to habitual behavior. ${ }^{133}$ 
Table 3. Effects of stress on instrumental behavior and on molecular determinants of behavior mediated by BLA, amygdala and BLA-NAcc connections

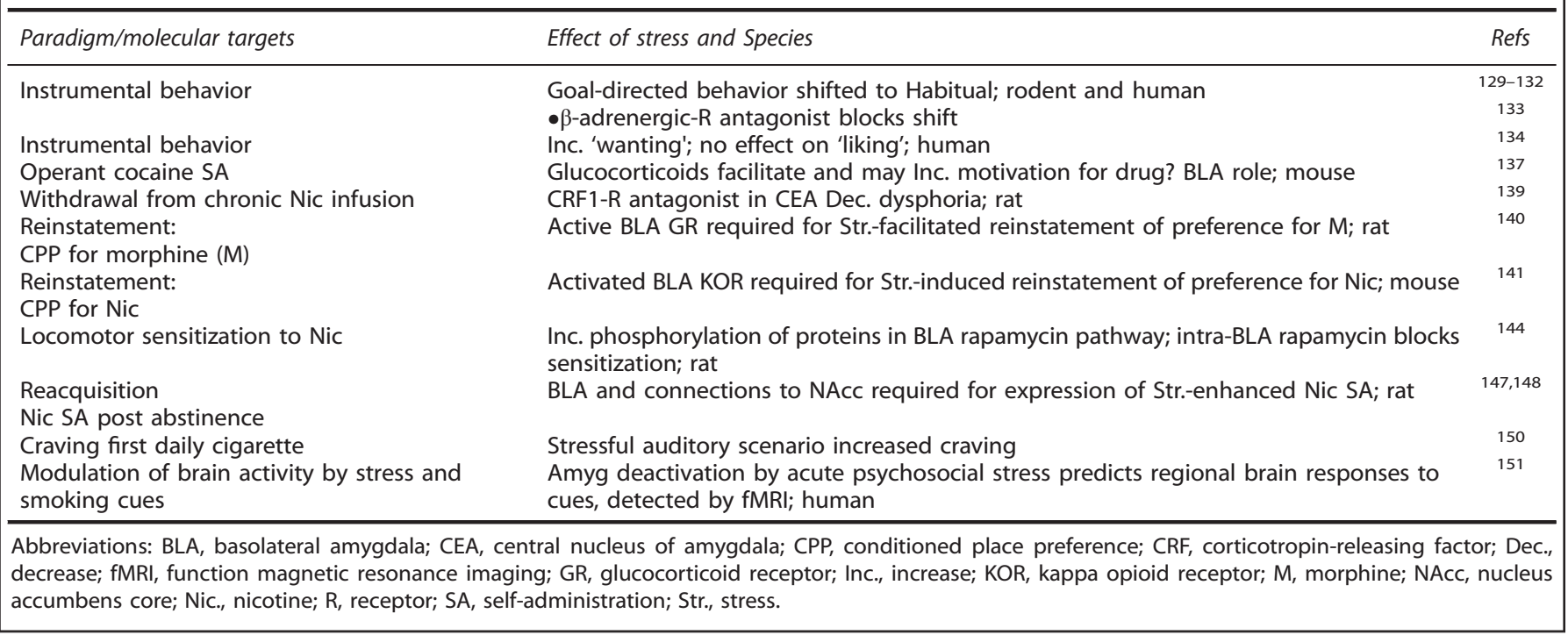

Stress also affects the 'wanting' or motivation to obtain a reward that is triggered by conditioned cues (for review of wanting and liking, Pool et al. $\left.{ }^{134}\right)$. In humans, stress specifically increases cue-induced wanting without affecting the 'liking' or hedonic pleasure of a sweet reward. ${ }^{135}$ Taken together, stress promotes habitual, 'non-cognitive' behaviors and amplifies the motivation for appetitive reward. In the next subsection, we address connections between BLA and NAcc that are involved in stress-enhanced motivation for appetitive nicotine reward.

Animal studies of interactions between stress, drug-related and other reward-related behaviors, and neural circuitry

Numerous animal studies have demonstrated a causal linkage between acute effects of stress on the extended amygdala and subsequent cue reactivity and drug self-administration (SA). ${ }^{136}$ Plasma glucocorticoid levels, elevated by stress, activate glucocorticoid receptors (GRs). The GR in D1R-positive postsynaptic neurons innervating the VTA, specifically the GABAergic neurons of NAc and glutamatergic neurons of PFC - modulate the function of these GABA and glutamate neurons, altering the activity of downstream VTA DA neurons. Absence of GR in these postsynaptic neurons greatly reduces the reinforcing properties and motivation to obtain cocaine, without affecting the acquisition of operant cocaine SA. ${ }^{137}$ Both DA neuron-firing rate and burst frequency are reduced by the absence of GR in these D1R-positive neurons. Thus, glucocorticoids facilitate the motivation to take addictive drugs and may enhance motivation when plasma levels are elevated by stress.

Acute exposure to a stressor, which is known to reinstate extinguished operant drug-seeking behavior (for example, for nicotine and cocaine), is a model for relapse to drug-taking behavior. ${ }^{136}$ Recent studies show that stress-induced reinstatement of nicotine-seeking behavior depends on the activation of circuits responsive to corticotropin-releasing factor. ${ }^{138}$ Corticotropin-releasing factor is also involved in the dysphoria induced by withdrawal from nicotine. ${ }^{139}$ Blockade of CRF1-R in the central nucleus of amygdala prevented the elevation of brain reward thresholds (indicative of reduced brain reward function) induced by mecamylamine-precipitated withdrawal from chronic nicotine. Corticotropin-releasing factor-positive neurons in central amygdala are also involved in mediating the effects of acute stress on reinstatement of seeking other addictive drugs (for example, cocaine).

Acute stress facilitates reinstatement of the extinguished conditioned place preference (CPP) for morphine; facilitation by stress depends on glucocorticoids. In a recent study, following extinction of CPP, rats received either forced swim stress or corticosterone, followed by an ineffective dose of morphine to induce reinstatement. ${ }^{140}$ The physical stress of forced swim, but not corticosterone alone, effectively induced CPP, and bilateral intra-BLA microinjection of mifepristone (RU38486, a GR antagonist) prevented this induction. Thus, activation of GR in BLA by stress appears to facilitate the rewarding effects of morphine. In this model, activation of GR is necessary, but not sufficient to reproduce the effects of stress.

Stress-induced reinstatement of CPP for nicotine also requires intact circuitry within mouse BLA. Kappa opioid receptors responsive to the opioid neuropeptide, dynorphin, have been implicated in this effect of stress (that is, footshock-induced reinstatement of nicotine preference). ${ }^{141}$ By selectively transfecting and inhibiting a specific subset of BLA neurons, using designer receptors activated by designer drugs (that is, DREADDs), G-protein signaling through Gai was found to mediate the kappa opioid receptor-dependent inhibition of CaMKlla-positive BLA neurons (that is, glutamatergic output neurons). Thus, the effects of acute footshock stress in the reinstatement of CPP for nicotine appear to require inhibition of BLA principal output neurons by kappa opioid receptors.

In addition to processing information related to stress, BLA has long been implicated in reinstatement of drug-seeking behavior stimulated by drug-conditioned cues and in sensitization to the effects of repeated exposure to drug. Bilateral lesions of BLA are known to prevent both cue-induced reinstatement of cocaine SA and acquisition of cocaine-seeking under a second-order schedule of reinforcement. ${ }^{142,143}$ Behavioral responses to drugs of abuse sensitize following repeated exposure to drug. Repetitive administration of nicotine causes locomotor sensitization in which a challenge dose of nicotine stimulates a significantly greater locomotor response after abstinence from repeated exposures to the drug. This sensitization is accompanied by increased phosphorylation of proteins in the mammalian target of rapamycin pathway (mTOR). ${ }^{144}$ In BLA and not CEA, proteins downstream of mTORC1 become phosphorylated (for example, p-p70s6k, p-4EBP). Both systemic and intra-BLA infusions of 
rapamycin, a potent inhibitor of mTOR, block the initiation and expression of locomotor sensitization to nicotine and the phosphorylation of proteins downstream of mTORC1. Thus, the rapamycin pathway in BLA is required for sensitization to repeated exposures to nicotine.

Only $3-5 \%$ of human cigarette quitters are successful for 612 months. Chronic stress is one of the most prominent inducers of relapse to cigarette smoking ${ }^{145}$ and drug taking, yet very few preclinical studies have focused on the relapse to drug taking induced by chronic, repeated stress during drug abstinence. ${ }^{146} \mathrm{We}$ recently established a model for relapse to operant nicotine SA. ${ }^{147}$ Following stable acquisition of SA by rats with $23 \mathrm{~h}$ access to intravenous nicotine in operant chambers, restraint stress was imposed for $30 \mathrm{~min}$ on alternate days during an 8-day interval of drug abstinence without extinction training. Following the fourth and final stress session, rats were returned to home operant chambers. Figure 3 shows that stress greatly increases the active lever presses, nicotine infusions and motivation to obtain the drug (that is, increased progressive ratio). In addition, stress increases the number of infusions obtained during the inactive phase (that is, lights on) of the light cycle. ${ }^{147}$

In further investigations, using chemical disconnection of serial connections between brain regions, we found that BLA and connections to NAcc are necessary for the expression of stressenhanced nicotine $S A$, as are connections between ventral hippocampus and BLA (see Figure 4). ${ }^{148}$ We also observed (unpublished studies) that both intravenous nicotine-stimulated glutamate and DA release, sampled by in vivo microdialysis of NAcc in freely moving rats, were significantly increased twentyfours after repeated stress (administered during abstinence from nicotine SA). This enhanced release of DA was abolished by inactivation of the ipsilateral BLA (glutamate response to inactivation of BLA has not been evaluated). Thus, repeated stress during abstinence increases the motivation to obtain nicotine and the amount taken. Although BLA projects to other regions (for example, cortical and dorsomedial striatum) involved in motivated behavior, the response to stress described in the foregoing experiments depends on intact BLA and connections to NAcc and ventral hippocampus. The stress-enhanced reacquisition of nicotine SA is associated with increased NAcc release of both glutamate (targeting medium spiny neurons modulated by D1R) and DA, which, in the case of DA, depends on intact BLA activity. $A$ recent study using real-time recording and optogenetic phototagging, showed that BLA neurons, specifically those connecting to NAc, were excited by cues predicting reward. ${ }^{149}$

In summary, both stress-induced reinstatement of extinguished drug seeking and reacquisition of nicotine taking require specific amygdaloid mechanisms, depending on the model and drug. Acute stress-induced reinstatement of CPP for drug and drug SA involve GR- and kappa opioid receptor-dependent mechanisms within BLA and corticotropin-releasing factor in CEA, respectively, and reacquisition of nicotine taking after chronic stress during abstinence, which enhances motivation for nicotine, involves BLA and its connections to NACc. Therefore, BLA and CEA responsiveness to stress modulates multiple brain regions controlling craving and motivation to take drug.

\section{SECTION 5. DRUG ADDICTION, BLA AND STRESS: INTEGRATION OF INSIGHTS FROM HUMAN CLINICAL AND BRAIN IMAGING STUDIES WITH ANIMAL MODELS OF BLA FUNCTION IN ADDICTION}

Human clinical and fMRI studies of interactions between stress, drug-related behaviors and neural circuitry

A controlled human laboratory study evaluated the effects of stress on electing to smoke the first cigarette of the day and on subsequent smoking. ${ }^{150}$ The randomized audio presentation of a
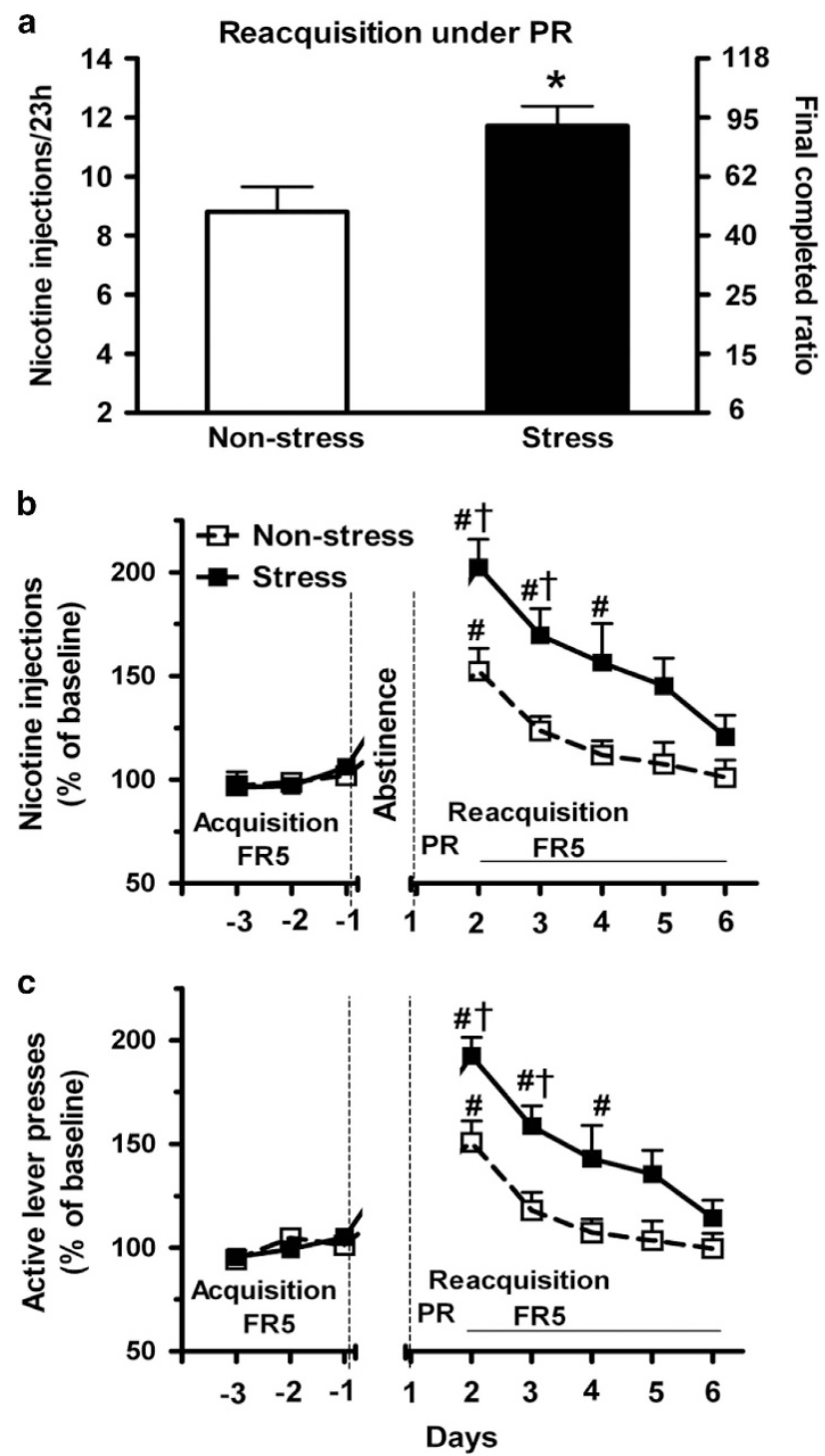

Figure 3. Repeated stress during abstinence increased the reacquisition of operant nicotine self-administration (SA). The reacquisition of nicotine SA was measured under a progressive ratio (PR) schedule begun immediately after the final stress on day 7 (30 min sessions of restraint in a plexiglass cylinder on days 1, 3, 5 and 7 of abstinence from nicotine SA) and followed by an FR5 (fixed ratio: 5 operant lever presses required to obtain 1 infusion of nicotine) schedule. (a) The number of nicotine injections and the final ratio completed under a PR schedule during a 23-h session of reacquisition were significantly increased by repeated restraint stress compared with the non-stress group. (b, c) After the PR session, both nicotine injections and active lever presses during 5 days of reacquisition under an FR5 schedule were also significantly increased by stress (repeated measure ANOVA: $P<0.05$ ). ${ }^{*} P<0.05$ versus non-stress groups ( $t$-test). ${ }^{\#} P<0.05$ versus baseline during the final 3 days of acquisition within group; ${ }^{\dagger} P<0.05$ stress versus non-stress group at same time interval ( $t$-test). $n=5$ and 7 for non-stress and stress groups, respectively. Reprinted from Yu et al. ${ }^{147}$ with permission from the publisher.

stressful personal scenario versus neutral scenario to an overnight abstinent smoker reduces the resistance to smoke the first morning cigarette and increases craving, which is diminished by smoking. In addition, puff number increases and interpuff interval declines while smoking the first cigarette after stress. In contrast to these findings, the number of subsequent smoked cigarettes is not affected by stress. Thus, acute stress increases craving for and 


\section{a

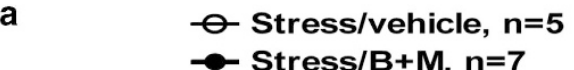

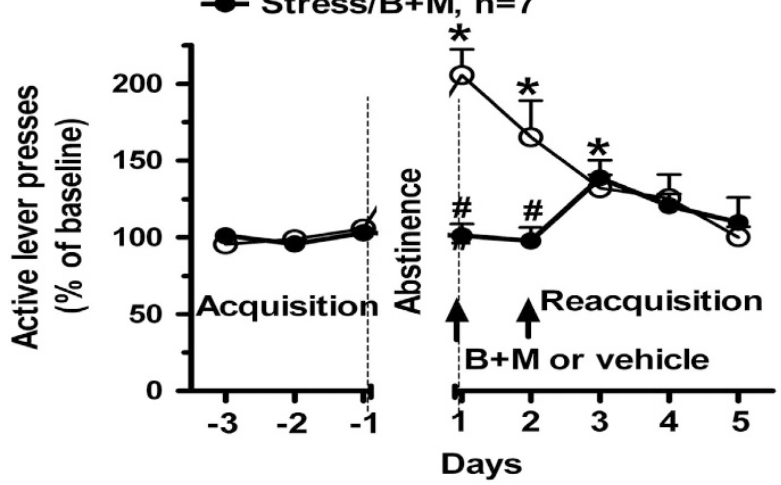
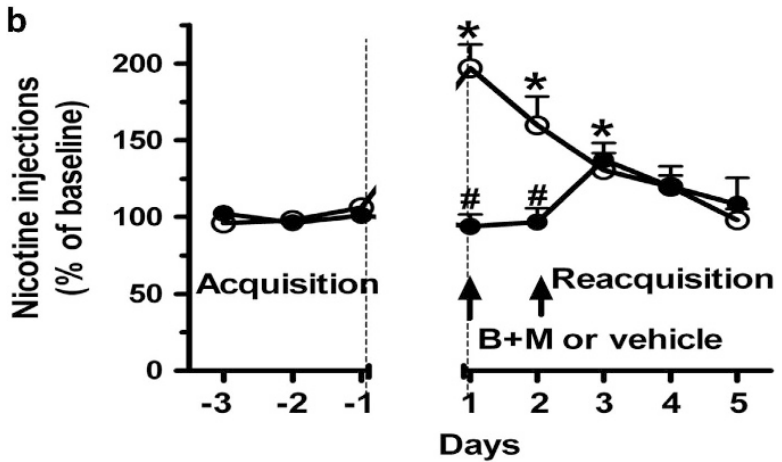

Figure 4. Reversible disconnection of basolateral amygdala (BLA) and nucleus accumbens core (NAcc) blocked the expression of stress-enhanced operant nicotine self-administration (SA) during reacquisition. GABA receptor agonists, baclofen and muscimol ( $B$ $+\mathrm{M})$, or vehicle, were microinjected unilaterally into BLA and contralaterally into NAcc 30 min prior to reacquisition sessions on d1 and 2 (indicated by arrows). Active lever presses and nicotine injections are shown in $\mathbf{a}$, $\mathbf{b}$, respectively. ${ }^{*} P<0.05$ for within-group comparisons of responses during reacquisition versus the final $3 \mathrm{~d}$ of acquisition (one-way ANOVA with post hoc Bonferroni comparisons); ${ }^{\#} P<0.05$ for stress/B+M versus stress/vehicle on the same $\mathrm{d}$ ( $t$-test). Reprinted from Yu and Sharp ${ }^{148}$ with permission from the publisher.

decreases resistance to smoking the first cigarette of the day in chronic smokers.

Functional MRI has been used to measure changes in human regional brain activity induced by acute stress and then by presentation of smoking-associated cues to chronic cigarette smokers. ${ }^{151}$ Psychosocial stress per se modulates the activity of the medial temporal lobe, which contains amygdala and hippocampus, and other limbic structures. The magnitude of deactivation in amygdala, hippocampus and NAc was used to define a brain index of stress that correlates with increased MRI responses to cue presentation in other brain regions such as medial PFC, medial temporal lobe and in primary and association visual areas. Thus, the brain response to acute psychosocial stress predicts subsequent regional neural responsiveness to smoking-associated cues, indicating that stress appears to enhance neural cue reactivity, perhaps by increasing the incentive salience of these cues.

Integration of human imaging studies of brain reactivity to salient drug cues and animal models of drug seeking

Human imaging studies demonstrate activation of mesocorticolimbic regions including amygdala, induced by the presentation of salient cues associated with drugs (for example, nicotine, cocaine and ethanol; for review, see Jasinka et al. ${ }^{152}$ ). These observations fit with the drug-induced release of DA throughout mesocorticolimbic regions by projections mainly from VTA, which has been widely reported in animal and human studies. Animal studies have characterized the receptors and neural mechanisms mediating DA release and the role of BLA in responding to drug-conditioned cues. $^{77-81}$

Regional brain reactivity to the presentation of salient drug cues, detected by fMRI, varies within and between human imaging studies and individuals, reflecting bidirectional interactions with the following factors: intensity and chronicity of drug use, depth of addiction, relapse risk, responsiveness to treatment, stressor exposure and abstinence and intensity of withdrawal. ${ }^{152}$ In smokers, although smoking cue-induced reactivity in many brain regions is positively associated with the degree of nicotine dependence, a negative correlation was found in the amygdala. ${ }^{153}$ In contrast, amygdala responses to ethanol-associated cues are positively correlated with the severity of ethanol addiction. ${ }^{154}$ In summary, human brain imaging has the unique capacity to illuminate individual differences in brain reactivity to cues, reflecting the complex patterns and individual variation in human addiction. Understanding the significance of these individual differences will require further development of differentiated animal behavioral models of addiction and analysis of the underlying neural dysregulation.

Animal models of reinstatement of extinguished drug-seeking behavior show that conditioned cues or stress acutely induce drug-seeking behavior for multiple drugs (for reviews, see Mantsch and et al. ${ }^{146}$ and $\mathrm{Koob}^{155}$ ). Bilateral lesions of rodent $B L A$ are known to prevent both cue-induced reinstatement of cocaine SA and acquisition of cocaine seeking under a secondorder schedule of reinforcement. ${ }^{142,143}$ A complementary human fMRI study showed that self-reported cigarette craving is positively correlated with amygdala reactivity to the presentation of a cigarette cue. ${ }^{156}$ In addition, an fMRI study (reviewed above Dagher ${ }^{151}$ ) demonstrates that the reactivity of several brain regions, including amygdala, to acute psychosocial stress predicts subsequent regional brain reactivity to smoking-associated cues. Lastly, in a study of individuals with heavy ethanol use, both anxiety and depressive symptoms were positively correlated with reactivity to gustatory ethanol cues in multiple brain regions. ${ }^{157}$

These studies underscore the essential roles of BLA and amygdala within the network of brain regions mediating diverse behavioral and physiological responses to conditioned cues and stressors. Both human fMRI research and the animal study of BLA inactivation indicate the essential role of this region in craving and craving-related behavioral responses to drug-conditioned cues. fMRI findings also suggest that amygdala responses to acute stress may modulate the effect of smoking-conditioned cues on the activation of a network of brain regions. This human study coheres with preclinical observations demonstrating that (i) stress acutely induces craving for drug-manifest as reinstated drug seeking behavior after extinction (discussed in section 4), and (ii) chronic stress during abstinence amplifies the motivation to take drugdue to enhanced signaling between BLA and NAcc. ${ }^{147,148}$ Furthermore, a complementary study indicates that glutamate, released by BLA principal neurons projecting to NAc, is required to promote motivated responding for natural reward (that is, sucrose). ${ }^{79}$ Although these studies highlight critical BLA-NAc monosynaptic connections, BLA connections to other brain regions may also be involved.

In summary, both human imaging studies and animal models indicate that drug-associated cues activate a multiregional neural network that includes the BLA. Inactivation of BLA disrupts drugtaking and drug-seeking behaviors. Human imaging studies show that regional brain responsivity to salient cues varies between individuals who differ by drug-related and environmental factors 
that affect brain function. Within this network of brain regions, the degree of dependence on nicotine versus ethanol may have opposite effects on amygdala reactivity. Both the acute cueinduced reinstatement of drug seeking and the chronic stressenhanced motivation to take drug after abstinence require activation of amygdala. Increased activity of amygdala, BLA and neural projections to NAc appears to enhance the motivation for drug reward.

\section{CONCLUSION}

Multiple neurotransmitters and receptors mediate the interregional communication of information (for example, visual and auditory) contributing to the emotive dimension of cognition and behavior. Diverse experimental approaches, utilizing genetic, molecular, electrophysiological, imaging and behavioral methodologies in animals and humans, have established the pivotal role of amygdala and BLA in processing and integrating this emotive information, in coordination with multiple brain regions. Chronic stress affects neural inputs to BLA, inducing neuroplasticity that causes hyperexcitability of BLA principal neurons. Stress disrupts the function of both intrinsic BLA GABAergic circuits (for example, altered $\mathrm{a}_{1 \mathrm{~A}}$ adrenoreceptor expression) that regulate principal neurons and the principal neurons (for example, altered SK channels and AHPs), per se. This hyperexcitability of BLA principal neurons is a major factor that sustains and exacerbates abnormal behaviors in PTSD, addiction and other behavioral disorders.

Both human imaging studies and animal studies indicate that drug-associated cues activate a multiregional neural network that includes the BLA. Within this network, the essential role of BLA is evident in the disruption of certain drug-taking and drug-seeking behaviors by inactivation of BLA. Both the acute cue-induced reinstatement of drug seeking (for example, nicotine, cocaine and heroin) and the chronic stress-enhanced motivation to take nicotine after abstinence are mediated, in part, by activation of amygdala and BLA. Human imaging studies also show that regional brain responsiveness to salient drug cues differ between individuals who vary by drug-related (for example, degree of dependence) and environmental factors (for example, stressors) that alter brain function. Thus, behavioral responses to drug cues can show considerable variation among individual addicts.

Acute and chronic stresses augment both craving and motivation for smoked cigarettes and nicotine by humans and animals, respectively. Moreover, human brain imaging has implicated amygdaloid responsiveness to acute stress as a determinant of the level of brain activity stimulated by smoking cues in multiple brain regions. The BLA and its glutamatergic inputs to NAC are also required for motivated responding for natural rewards. Stress-induced hyperexcitability of these projections from BLA principal neurons to NAc appears to enhance the motivation for nicotine reward following abstinence from the drug. In general, hyperexcitability of BLA principal neurons has a major role in human addiction, anxiety and fear-related disorders.

\section{CONFLICT OF INTEREST}

The author declares no conflict of interest.

\section{REFERENCES}

1 Prager EM, Bergstrom HC, Wynn GH, Braga MF. The basolateral amygdala gamma-aminobutyric acidergic system in health and disease. I Neurosci Res 2016; 94: 548-567.

2 Hadley D, Wu ZL, Kao C, Kini A, Mohamed-Hadley A, Thomas K et al. The impact of the metabotropic glutamate receptor and other gene family interaction networks on autism. Nat Commun 2014; 5: 4074-4082.
3 Elia J, Glessner JT, Wang K, Takahashi N, Shtir CJ, Hadley D et al. Genome-wide copy number variation study associates metabotropic glutamate receptor gene networks with attention deficit hyperactivity disorder. Nat Genet 2011; 44: 78-84.

4 Yu X, Liu L, Chen W, Cao Q, Zepf FD, Ji G et al. Integrity of amygdala subregionbased functional networks and emotional lability in drug-naive boys with ADHD. J Atten Disord 2016; 18: pii: pyv0171087054716661419 [e-pub ahead of print].

5 Capogna M. GABAergic cell type diversity in the basolateral amygdala. Curr Opin Neurobiol 2014; 26: 110-116.

6 Pitkanen A. Connectivity of the Rat Amygdaloid Complex. Aggelton JP (ed). Oxford University Press: Oxford, UK, 2000.

7 McDonald AJ. Topographical organization of amygdaloid projections to the caudatoputamen, nucleus accumbens, and related striatal-like areas of the rat brain. Neuroscience 1991; 44: 15-33.

8 Pare D, Gaudreau H. Projection cells and interneurons of the lateral and basolateral amygdala: distinct firing patterns and differential relation to theta and delta rhythms in conscious cats. J Neurosci 1996; 16: 3334-3350.

9 Terburg D, Morgan BE, Montoya ER, Hooge IT, Thornton HB, Hariri AR et al. Hypervigilance for fear after basolateral amygdala damage in humans. Transl Psychiatry 2012; 2: e115.

10 Nuss P. Anxiety disorders and GABA neurotransmission: a disturbance of modulation. Neuropsychiatr Dis Treat 2015; 11: 165-175.

11 Truitt WA, Sajdyk TJ, Dietrich AD, Oberlin B, McDougle CJ, Shekhar A. From anxiety to autism: spectrum of abnormal social behaviors modeled by progressive disruption of inhibitory neuronal function in the basolateral amygdala in Wistar rats. Psychopharmacology 2007; 191: 107-118.

12 Martin BS, Corbin JG, Huntsman MM. Deficient tonic GABAergic conductance and synaptic balance in the fragile $X$ syndrome amygdala. J Neurophysiol 2014; 112: 890-902.

13 Klein RC, Acheson SK, Mace BE, Sullivan PM, Moore SD. Altered neurotransmission in the lateral amygdala in aged human apoE4 targeted replacement mice. Neurobiol Aging 2014; 35: 2046-2052.

14 Cunningham MG, Connor CM, Carlezon WA Jr, Meloni E. Amygdalar GABAergicrich neural grafts attenuate anxiety-like behavior in rats. Behav Brain Res 2009; 205: 146-153.

15 Segman RH, Shefi N, Goltser-Dubner T, Friedman N, Kaminski N, Shalev AY. Peripheral blood mononuclear cell gene expression profiles identify emergent post-traumatic stress disorder among trauma survivors. Mol Psychiatry 2005; 10: 500-513, 425 .

16 Hsu FC, Zhang GJ, Raol YS, Valentino RJ, Coulter DA, Brooks-Kayal AR. Repeated neonatal handling with maternal separation permanently alters hippocampal GABAA receptors and behavioral stress responses. Proc Natl Acad Sci USA 2003; 100: 12213-12218.

17 Karssen AM, Her S, Li JZ, Patel PD, Meng F, Bunney WE Jr et al. Stress-induced changes in primate prefrontal profiles of gene expression. Mol Psychiatry 2007; 12: 1089-1102.

18 Nelson EC, Agrawal A, Pergadia ML, Lynskey MT, Todorov AA, Wang JC et al. Association of childhood trauma exposure and GABRA2 polymorphisms with risk of posttraumatic stress disorder in adults. Mol Psychiatry 2009; 14: 234-235.

19 Wolff SB, Grundemann J, Tovote P, Krabbe S, Jacobson GA, Muller C et al. Amygdala interneuron subtypes control fear learning through disinhibition. Nature 2014; 509: 453-458.

20 Sanders SK, Shekhar A. Regulation of anxiety by GABAA receptors in the rat amygdala. Pharmacol Biochem Behav 1995; 52: 701-706.

21 Lehner M, Wislowska-Stanek A, Skorzewska A, Maciejak P, Szyndler J, Turzynska $D$ et al. Differences in the density of GABA-A receptor alpha-2 subunits and gephyrin in brain structures of rats selected for low and high anxiety in basal and fear-stimulated conditions, in a model of contextual fear conditioning. Neurobiol Learn Mem 2010; 94: 499-508.

22 Braga MF, Aroniadou-Anderjaska V, Manion ST, Hough CJ, Li H. Stress impairs alpha(1 A) adrenoceptor-mediated noradrenergic facilitation of GABAergic transmission in the basolateral amygdala. Neuropsychopharmacology 2004; 29: 45-58.

23 Almeida-Suhett CP, Prager EM, Pidoplichko V, Figueiredo TH, Marini AM, Li Z et al. Reduced GABAergic inhibition in the basolateral amygdala and the development of anxiety-like behaviors after mild traumatic brain injury. PLoS ONE 2014; 9: e102627.

24 Chhatwal JP, Stanek-Rattiner L, Davis M, Ressler KJ. Amygdala BDNF signaling is required for consolidation but not encoding of extinction. Nat Neurosci 2006; 9: 870-872.

25 Egan MF, Kojima M, Callicott JH, Goldberg TE, Kolachana BS, Bertolino A et al. The BDNF val66met polymorphism affects activity-dependent secretion of BDNF and human memory and hippocampal function. Cell 2003; 112: 257-269. 
26 Soliman F, Glatt CE, Bath KG, Levita L, Jones RM, Pattwell SS et al. A genetic variant BDNF polymorphism alters extinction learning in both mouse and human. Science 2010; 327: 863-866.

27 Muhlberger A, Andreatta M, Ewald H, Glotzbach-Schoon E, Troger C, Baumann C et al. The BDNF Val66Met polymorphism modulates the generalization of cued fear responses to a novel context. Neuropsychopharmacology 2014; 39: 1187-1195.

28 Galvin C, Lee FS, Ninan I. Alteration of the centromedial amygdala glutamatergic synapses by the BDNF Val66Met polymorphism. Neuropsychopharmacology 2015; 40: 2269-2277.

29 Faber ES, Delaney AJ, Power JM, Sedlak PL, Crane JW, Sah P. Modulation of SK channel trafficking by beta adrenoceptors enhances excitatory synaptic transmission and plasticity in the amygdala. J Neurosci 2008; 28: 10803-10813.

30 Hopf FW, Seif T, Mohamedi ML, Chen BT, Bonci A. The small-conductance calcium-activated potassium channel is a key modulator of firing and long-term depression in the dorsal striatum. Eur J Neurosci 2010; 31: 1946-1959.

31 Muller JF, Mascagni F, McDonald AJ. Pyramidal cells of the rat basolateral amygdala: synaptology and innervation by parvalbumin-immunoreactive interneurons. J Comp Neurol 2006; 494: 635-650.

32 Unal CT, Pare D, Zaborszky L. Impact of basal forebrain cholinergic inputs on basolateral amygdala neurons. J Neurosci 2015; 35: 853-863.

33 Smith Y, Pare JF, Pare D. Differential innervation of parvalbumin-immunoreactive interneurons of the basolateral amygdaloid complex by cortical and intrinsic inputs. J Comp Neurol 2000; 416: 496-508.

34 Martin BS, Corbin JG, Huntsman MM. Deficient tonic GABAergic conductance and synaptic balance in the fragile X syndrome amygdala. $J$ Neurophysiol 2014; 112: 891-902.

35 Woodruff AR, Sah P. Inhibition and synchronization of basal amygdala spiking by parvalbumin-positive interneurons. J Neurophysiol 2007; 98: 2956-2961.

36 Woodruff AR, Sah P. Networks of parvalbumin-positive interneurons in the basolateral amygdala. J Neurosci 2007; 27: 553-563.

37 McDonald AJ, Mascagni F. Localization of the CB1 type cannabinoid receptor in the rat basolateral amygdala: high concentrations in a subpopulation of cholecystokinin-containing interneurons. Neuroscience 2001; 107: 641-652.

38 Stein C, Davidowa H, Albrecht D. 5-HT(1A) receptor-mediated inhibition and $5-\mathrm{HT}(2)$ as well as $5-\mathrm{HT}(3)$ receptor-mediated excitation in different subdivisions of the rat amygdala. Synapse 2000; 38: 328-337.

39 McDonald AJ, Mascagni F, Muller JF. Immunocytochemical localization of GABABR1 receptor subunits in the basolateral amygdala. Brain Res 2004; 1018: 147-158

40 Fallon J, Ciofi P. Distribution of Monoamines within the Amygdala. IA J (ed). Academic Press: New York, 1992.

41 Pinard CR, Muller JF, Mascagni F, McDonald AJ. Dopaminergic innervation of interneurons in the rat basolateral amygdala. Neuroscience 2008; 157: 850-863.

42 Chu HY, Ito W, Li J, Morozov A. Target-specific suppression of GABA release from parvalbumin interneurons in the basolateral amygdala by. J Neurosci 2012; 32: 14815-14820.

43 Bissiere S, Humeau Y, Luthi A. Dopamine gates LTP induction in lateral amygdala by suppressing feedforward inhibition. Nat Neurosci 2003; 6: 587-592.

44 Kroner S, Rosenkranz JA, Grace AA, Barrionuevo G. Dopamine modulates excitability of basolateral amygdala neurons in vitro. J Neurophysiol 2005; 93: 1598-1610.

45 Brinley-Reed M, McDonald AJ. Evidence that dopaminergic axons provide a dense innervation of specific neuronal subpopulations in the rat basolateral amygdala. Brain Res 1999; 850: 127-135.

46 Buffalari DM, Grace AA. Noradrenergic modulation of basolateral amygdala neuronal activity: opposing influences of alpha-2 and beta receptor activation. J Neurosci 2007; 27: 12358-12366.

47 Braga MF, Aroniadou-Anderjaska V, Li H. The physiological role of kainate receptors in the amygdala. Mol Neurobiol 2004; 30: 127-141.

48 Gotti C, Clementi F, Fornari A, Gaimarri A, Guiducci S, Manfredi I et al. Structura and functional diversity of native brain neuronal nicotinic receptors. Biochem Pharmacol 2009; 78: 703-711.

49 Hill JA Jr, Zoli M, Bourgeois JP, Changeux JP. Immunocytochemical localization of a neuronal nicotinic receptor: the beta 2-subunit. J Neurosci 1993; 13 1551-1568.

50 Pidoplichko VI, Prager EM, Aroniadou-Anderjaska V, Braga MF. alpha7Containing nicotinic acetylcholine receptors on interneurons of the basolateral amygdala and their role in the regulation of the network excitability. $J$ Neurophysiol 2013; 110: 2358-2369.

51 Mahanty NK, Sah P. Calcium-permeable AMPA receptors mediate long-term potentiation in interneurons in the amygdala. Nature 1998; 394: 683-687.

52 Polepalli JS, Sullivan RK, Yanagawa Y, Sah P. A specific class of interneuron mediates inhibitory plasticity in the lateral amygdala. J Neurosci 2010; 30: 14619-14629.
53 Unal G, Pare JF, Smith Y, Pare D. Cortical inputs innervate calbindinimmunoreactive interneurons of the rat basolateral amygdaloid complex. J Comp Neurol 2014; 522: 1915-1928.

54 McDonald AJ, Mascagni F. Neuronal localization of 5-HT type 2 A receptor immunoreactivity in the rat basolateral amygdala. Neuroscience 2007; 146: 306-320.

55 Rainnie DG, Asprodini EK, Shinnick-Gallagher P. Inhibitory transmission in the basolateral amygdala. J Neurophysiol 1991; 66: 999-1009.

56 Sah P, Faber ES, Lopez De Armentia M, Power J. The amygdaloid complex: anatomy and physiology. Physiol Rev 2003; 83: 80.

57 Muller JF, Mascagni F, Zaric V, McDonald AJ. Muscarinic cholinergic receptor M1 in the rat basolateral amygdala: ultrastructural localization and synaptic relationships to cholinergic axons. J Comp Neurol 2013; 521: 1743-1759.

58 Bombardi C. Distribution of 5-HT2A receptor immunoreactivity in the rat amygdaloid complex and colocalization with gamma-aminobutyric acid. Brain Res 2011; 1370: 112-128.

59 Braas KM, Newby AC, Wilson VS, Snyder SH. Adenosine-containing neurons in the brain localized by immunocytochemistry. J Neurosci 1986; 6: 1952-1961.

60 Abbracchio MP, Burnstock G, Verkhratsky A, Zimmermann H. Purinergic signalling in the nervous system: an overview. Trends Neurosci 2009; 32: 19-29.

61 Dunwiddie TV, Taylor M, Heginbotham LR, Proctor WR. Long-term increases in excitability in the CA1 region of rat hippocampus induced by beta-adrenergic stimulation: possible mediation by cAMP. J Neurosci 1992; 12: 506-517.

62 Rau AR, Ariwodola OJ, Weiner JL. Postsynaptic adenosine A2A receptors modulate intrinsic excitability of pyramidal cells in the rat basolateral amygdala. Int J Neuropsychopharmacol 2015; 18: pii: pyv017.

63 Rau AR, Chappell AM, Butler TR, Ariwodola OJ, Weiner JL. Increased basolateral amygdala pyramidal cell excitability may contribute to the anxiogenic phenotype induced by chronic early-life stress. J Neurosci 2015; 35: 9730-9740.

64 Hetzel A, Rosenkranz JA. Distinct effects of repeated restraint stress on basolateral amygdala neuronal membrane properties in resilient adolescent and adult rats. Neuropsychopharmacology 2014; 39: 2114-2130.

65 Rau AR, Ariwodola OJ, Weiner JL. Presynaptic adenosine A(1) receptors modulate excitatory transmission in the rat basolateral amygdala. Neuropharmacology 2014; 77: 465-474.

66 Rosenkranz JA, Grace AA. Modulation of basolateral amygdala neuronal firing and afferent drive by dopamine receptor activation in vivo. J Neurosci 1999; 19: 11027-11039.

67 Sesack SR, Pickel VM. In the rat medial nucleus accumbens, hippocampal and catecholaminergic terminals converge on spiny neurons and are in apposition to each other. Brain Res 1990; 527: 266-279.

68 Mulder AB, Hodenpijl MG, Lopes da Silva FH. Electrophysiology of the hippocampal and amygdaloid projections to the nucleus accumbens of the rat: convergence, segregation, and interaction of inputs. J Neurosci 1998; 18: 5095-5102.

69 Johnson LR, Aylward RL, Hussain Z, Totterdell S. Input from the amygdala to the rat nucleus accumbens: its relationship with tyrosine hydroxylase immunoreactivity and identified neurons. Neuroscience 1994; 61: 851-865.

70 Garris PA, Ciolkowski EL, Pastore P, Wightman RM. Efflux of dopamine from the synaptic cleft in the nucleus accumbens of the rat brain. J Neurosci 1994; 14: 6084-6093.

71 Descarries L, Watkins KC, Garcia S, Bosler O, Doucet G. Dual character, asynaptic and synaptic, of the dopamine innervation in adult rat neostriatum: a quantitative autoradiographic and immunocytochemical analysis. J Comp Neurol 1996 375: 167-186.

72 Floresco SB, Blaha CD, Yang CR, Phillips AG. Dopamine D1 and NMDA receptors mediate potentiation of basolateral amygdala-evoked firing of nucleus accumbens neurons. J Neurosci 2001; 21: 6370-6376.

73 Yim CY, Mogenson GJ. Response of nucleus accumbens neurons to amygdala stimulation and its modification by dopamine. Brain Res 1982; 239: 401-415.

74 O'Donnell P, Grace AA. Dopaminergic reduction of excitability in nucleus accumbens neurons recorded in vitro. Neuropsychopharmacology 1996; 15: 87-97.

75 Smith-Roe SL, Kelley AE. Coincident activation of NMDA and dopamine D1 receptors within the nucleus accumbens core is required for appetitive instrumental learning. J Neurosci 2000; 20: 7737-7742.

76 Howland JG, Taepavarapruk P, Phillips AG. Glutamate receptor-dependent modulation of dopamine efflux in the nucleus accumbens by basolateral, but not central, nucleus of the amygdala in rats. J Neurosci 2002; 22: 1137-1145.

77 Cador M, Robbins TW, Everitt BJ. Involvement of the amygdala in stimulus-reward associations: interaction with the ventral striatum. Neuroscience 1989; 30: 77-86.

78 Everitt BJ, Morris KA, O'Brien A, Robbins TW. The basolateral amygdala-ventral striatal system and conditioned place preference: further evidence of limbicstriatal interactions underlying reward-related processes. Neuroscience 1991 42: 1-18. 
79 Stuber GD, Sparta DR, Stamatakis AM, van Leeuwen WA, Hardjoprajitno JE, Cho S et al. Amygdala to nucleus accumbens excitatory transmission facilitates reward seeking. Nature 2011; 475: 377-380.

80 Everitt BJ, Cardinal RN, Parkinson JA, Robbins TW. Appetitive behavior: impact of amygdala-dependent mechanisms of emotional learning. Ann N Y Acad Sci 2003; 985: 233-250.

81 Robbins TW, Ersche KD, Everitt BJ. Drug addiction and the memory systems of the brain. Ann N Y Acad Sci 2008; 1141: 1-21.

82 Di Ciano P, Everitt BJ. Direct interactions between the basolateral amygdala and nucleus accumbens core underlie cocaine-seeking behavior by rats. J Neurosci 2004; 24: 7167-7173.

83 Brog JS, Salyapongse A, Deutch AY, Zahm DS. The patterns of afferent innervation of the core and shell in the "accumbens" part of the rat ventral striatum: immunohistochemical detection of retrogradely transported fluoro-gold. J Comp Neurol 1993; 338: 255-278.

84 Christie MJ, Summers RJ, Stephenson JA, Cook CJ, Beart PM. Excitatory amino acid projections to the nucleus accumbens septi in the rat: a retrograde transport study utilizing $D[3 \mathrm{H}]$ aspartate and $[3 \mathrm{H}] \mathrm{GABA}$. Neuroscience 1987; 22: 425-439.

85 Rouillon C, Abraini JH, David HN. Prefrontal cortex and basolateral amygdala modulation of dopamine-mediated locomotion in the nucleus accumbens core. Exp Neurol 2008; 212: 213-217.

86 Noel X, Brevers D, Bechara A. A neurocognitive approach to understanding the neurobiology of addiction. Curr Opin Neurobiol 2013; 23: 632-638.

87 Ambroggi F, Ishikawa A, Fields HL, Nicola SM. Basolateral amygdala neurons facilitate reward-seeking behavior by exciting nucleus accumbens neurons. Neuron 2008; 59: 648-661.

88 Belova MA, Paton JJ, Morrison SE, Salzman CD. Expectation modulates neural responses to pleasant and aversive stimuli in primate amygdala. Neuron 2007; 55: 970-984.

89 Sugase-Miyamoto Y, Richmond BJ. Neuronal signals in the monkey basolateral amygdala during reward schedules. J Neurosci 2005; 25: 11071-11083.

90 Day JJ, Roitman MF, Wightman RM, Carelli RM. Associative learning mediates dynamic shifts in dopamine signaling in the nucleus accumbens. Nat Neurosci 2007; 10: 1020-1028.

91 Salamone JD, Correa M, Farrar A, Mingote SM. Effort-related functions of nucleus accumbens dopamine and associated forebrain circuits. Psychopharmacology 2007; 191: 461-482.

92 Nicola SM. The flexible approach hypothesis: unification of effort and cueresponding hypotheses for the role of nucleus accumbens dopamine in the activation of reward-seeking behavior. J Neurosci 2010; 30: 16585-16600.

93 Skorzewska A, Lehner M, Wislowska-Stanek A, Krzascik P, Ziemba A, Plaznik A. The effect of chronic administration of corticosterone on anxiety- and depression-like behavior and the expression of GABA-A receptor alpha-2 subunits in brain structures of low- and high-anxiety rats. Horm Behav 2014; 65: 6-13.

94 Williams $C L$, Men D, Clayton EC. The effects of noradrenergic activation of the nucleus tractus solitarius on memory and in potentiating norepinephrine release in the amygdala. Behav Neurosci 2000; 114: 1131-1144.

95 Galvez R, Mesches MH, McGaugh JL. Norepinephrine release in the amygdala in response to footshock stimulation. Neurobiol Learn Mem 1996; 66: 253-257.

96 Kaneko K, Tamamaki N, Owada H, Kakizaki T, Kume N, Totsuka M et al. Noradrenergic excitation of a subpopulation of GABAergic cells in the basolateral amygdala via both activation of nonselective cationic conductance and suppression of resting $\mathrm{K}+$ conductance: a study using glutamate decarboxylase 67-green fluorescent protein knock-in mice. Neuroscience 2008; 157: 781-797.

97 Ferry B, Roozendaal B, McGaugh JL. Basolateral amygdala noradrenergic influences on memory storage are mediated by an interaction between beta- and alpha1-adrenoceptors. J Neurosci 1999; 19: 5119-5123.

98 Miyahara S, Komori T, Fujiwara R, Shizuya K, Yamamoto M, Ohmori M et al. Effects of single and repeated stresses on the expression of mRNA for alpha1adrenoceptors in the rat hypothalamus and midbrain. Eur J Pharmacol 1999; 379: $111-114$

99 Miller LG, Thompson ML, Greenblatt DJ, Deutsch SI, Shader RI, Paul SM. Rapid increase in brain benzodiazepine receptor binding following defeat stress in mice. Brain Res 1987; 414: 395-400.

100 Bremner JD, Innis RB, Southwick SM, Staib L, Zoghbi S, Charney DS. Decreased benzodiazepine receptor binding in prefrontal cortex in combat-related posttraumatic stress disorder. Am J Psychiatry 2000; 157: 1120-1126.

101 Geuze E, van Berckel BN, Lammertsma AA, Boellaard R, de Kloet CS, Vermetten E et al. Reduced GABAA benzodiazepine receptor binding in veterans with posttraumatic stress disorder. Mol Psychiatry 2008; 13: 74-83, 3.

102 Caldji C, Francis D, Sharma S, Plotsky PM, Meaney MJ. The effects of early rearing environment on the development of GABAA and central benzodiazepine receptor levels and novelty-induced fearfulness in the rat. Neuropsychopharmacology 2000; 22: 219-229.

103 Santini E, Quirk GJ, Porter JT. Fear conditioning and extinction differentially modify the intrinsic excitability of infralimbic neurons. J Neurosci 2008; 28: 4028-4036.

104 McKay BM, Matthews EA, Oliveira FA, Disterhoft JF. Intrinsic neuronal excitability is reversibly altered by a single experience in fear conditioning. J Neurophysiol 2009; 102: 2763-2770.

105 Razzoli M, Carboni L, Andreoli M, Ballottari A, Arban R. Different susceptibility to social defeat stress of BalbC and C57BL6/J mice. Behav Brain Res 2011; 216: 100-108.

106 Fuchsl AM, Neumann ID, Reber SO. Stress resilience: a low-anxiety genotype protects male mice from the consequences of chronic psychosocial stress. Endocrinology 2014; 155: 117-126.

107 Krishnan V, Han MH, Graham DL, Berton O, Renthal W, Russo SJ et al. Molecular adaptations underlying susceptibility and resistance to social defeat in brain reward regions. Cell 2007; 131: 391-404.

108 Rauch SL, Whalen PJ, Shin LM, Mclnerney SC, Macklin ML, Lasko NB et al. Exaggerated amygdala response to masked facial stimuli in posttraumatic stress disorder: a functional MRI study. Biol Psychiatry 2000; 47: 769-776.

109 Esteves F, Ohman A. Masking the face: recognition of emotional facial expressions as a function of the parameters of backward masking. Scand J Psychol 1993; 34: 1-18.

110 Whalen PJ, Rauch SL, Etcoff NL, Mclnerney SC, Lee MB, Jenike MA. Masked presentations of emotional facial expressions modulate amygdala activity without explicit knowledge. J Neurosci 1998; 18: 411-418.

111 Rauch SL, Shin LM, Phelps EA. Neurocircuitry models of posttraumatic stress disorder and extinction: human neuroimaging research--past, present, and future. Biol Psychiatry 2006; 60: 376-382.

112 Mahan AL, Ressler KJ. Fear conditioning, synaptic plasticity and the amygdala: implications for posttraumatic stress disorder. Trends Neurosci 2012; 35: 24-35.

113 Asan E. Ultrastructural features of tyrosine-hydroxylase-immunoreactive afferents and their targets in the rat amygdala. Cell Tissue Res 1997; 288: 449-469.

114 Herman JP, Guillonneau D, Dantzer R, Scatton B, Semerdjian-Rouquier L, Le Moal M. Differential effects of inescapable footshocks and of stimuli previously paired with inescapable footshocks on dopamine turnover in cortical and limbic areas of the rat. Life Sci 1982; 30: 2207-2214.

115 Coco ML, Kuhn CM, Ely TD, Kilts CD. Selective activation of mesoamygdaloid dopamine neurons by conditioned stress: attenuation by diazepam. Brain Res 1992; 590: 39-47.

116 Harmer CJ, Phillips GD. Enhanced dopamine efflux in the amygdala by a predictive, but not a non-predictive, stimulus: facilitation by prior repeated D-amphetamine. Neuroscience 1999; 90: 119-130.

117 Hori K, Tanaka J, Nomura M. Effects of discrimination learning on the rat amygdala dopamine release: a microdialysis study. Brain Res 1993; 621: 296-300.

118 Inglis FM, Moghaddam B. Dopaminergic innervation of the amygdala is highly responsive to stress. J Neurochem 1999; 72: 1088-1094.

119 Borowski TB, Kokkinidis L. Contribution of ventral tegmental area dopamine neurons to expression of conditional fear: effects of electrical stimulation, excitotoxin lesions, and quinpirole infusion on potentiated startle in rats. Behav Neurosci 1996; 110: 1349-1364.

120 Lamont EW, Kokkinidis L. Infusion of the dopamine D1 receptor antagonist SCH 23390 into the amygdala blocks fear expression in a potentiated startle paradigm. Brain Res 1998; 795: 128-136.

121 Nader K, LeDoux J. The dopaminergic modulation of fear: quinpirole impairs the recall of emotional memories in rats. Behav Neurosci 1999; 113: 152-165.

122 Hitchcott PK, Bonardi CM, Phillips GD. Enhanced stimulus-reward learning by intra-amygdala administration of a D3 dopamine receptor agonist. Psychopharmacology 1997; 133: 240-248.

123 Miyajima M, Ozaki M, Wada K, Sekiguchi M. Noradrenaline-induced spontaneous inhibitory postsynaptic currents in mouse basolateral nucleus of amygdala pyramidal neurons: comparison with dopamine-induced currents. Neurosci Lett 2010; 480: 167-172.

124 Sarabdjitsingh RA, Kofink D, Karst H, de Kloet ER, Joels M. Stress-induced enhancement of mouse amygdalar synaptic plasticity depends on glucocorticoid and $\beta$-adrenergic activity. PLoS ONE 2012; 7: e42143.

125 Kavushansky A, Richter-Levin G. Effects of stress and corticosterone on activity and plasticity in the amygdala. J Neurosci Res 2006; 84: 1580-1587.

126 Chen H, Fu Y, Sharp BM. Chronic nicotine self-administration augments hypothalamic-pituitary-adrenal responses to mild acute stress. Neuropsychopharmacology 2008; 33: 721-730.

127 Matta SG, Valentine JD, Sharp BM. Nicotine activates NPY and catecholaminergic neurons in brainstem regions involved in ACTH secretion. Brain Res 1997; 759: 259-269. 
128 Joels M, Baram TZ. The neuro-symphony of stress. Nature Rev Neurosci 2009; 10: 459-466.

129 Balleine BW, Delgado MR, Hikosaka O. The role of the dorsal striatum in reward and decision making. J Neurosci 2007; 27: 8161-8165.

130 Balleine BW, Dickinson A. Goal-directed instrumental action: contingency and incentive learning and their cortical substrates. Neuropharmacology 1998; 37 407-419.

131 Schwabe L, Wolf OT. Stress prompts habit behavior in humans. J Neurosci 2009; 29: 7191-7198.

132 Dias-Ferreira E, Sousa JC, Melo I, Morgado P, Mesquita AR, Cerqueira J et al. Chronic stress causes frontostriatal reorganization and affects decision-making. Science 2009; 325: 621-625.

133 Schwabe L, Hoffken O, Tegenthoff M, Wolf OT. Preventing the stress-induced shift from goal-directed to habit action with a beta-adrenergic antagonist. J Neurosci 2011; 31: 17317-17325.

134 Pool E, Sennwald V, Delplanque S, Brosch T, Sander D. Measuring wanting and liking from animals to humans: a systematic review. Neurosci Biobehav Rev 2016; 63: 124-142.

135 Pool E, Brosch T, Delplanque S, Sander D. Stress increases cue-triggered "wanting" for sweet reward in humans. J Exp Psychol Anim Learn Cogn 2015; 41: 128-136.

136 Shaham Y, Shalev U, Lu L, De Wit H, Stewart J. The reinstatement model of drug relapse: history, methodology and major findings. Psychopharmacology 2003; 168: 3-20.

137 Ambroggi F, Turiault M, Milet A, Deroche-Gamonet V, Parnaudeau S, Balado E et al. Stress and addiction: glucocorticoid receptor in dopaminoceptive neurons facilitates cocaine seeking. Nat Neurosci 2009; 12: 247-249.

138 Zislis G, Desai TV, Prado M, Shah HP, Bruijnzeel AW. Effects of the CRF receptor antagonist D-Phe CRF(12-41) and the alpha2-adrenergic receptor agonist clonidine on stress-induced reinstatement of nicotine-seeking behavior in rats. Neuropharmacology 2007; 53: 958-966.

139 Bruijnzeel AW, Ford J, Rogers JA, Scheick S, Ji Y, Bishnoi M et al. Blockade of CRF1 receptors in the central nucleus of the amygdala attenuates the dysphoria associated with nicotine withdrawal in rats. Pharmacol Biochem Behav 2012; 101 62-68.

140 Karimi S, Attarzadeh-Yazdi G, Yazdi-Ravandi S, Hesam S, Azizi P, Razavi Y et al. Forced swim stress but not exogenous corticosterone could induce the reinstatement of extinguished morphine conditioned place preference in rats: involvement of glucocorticoid receptors in the basolateral amygdala. Behav Brain Res 2014; 264: 43-50.

141 Nygard SK, Hourguettes NJ, Sobczak GG, Carlezon WA, Bruchas MR. Stress induced reinstatement of nicotine preference requires dynorphin/kappa opioid activity in the basolateral amygdala. J Neurosci 2016; 36: 9937-9948.

142 Meil WM, See RE. Lesions of the basolateral amygdala abolish the ability of drug associated cues to reinstate responding during withdrawal from selfadministered cocaine. Behav Brain Res 1997; 87: 139-148.

143 Whitelaw RB, Markou A, Robbins TW, Everitt BJ. Excitotoxic lesions of the basolateral amygdala impair the acquisition of cocaine-seeking behaviour under a second-order schedule of reinforcement. Psychopharmacol 1996; 127: 213-224
144 Gao Y, Peng S, Wen Q, Zheng C, Lin J, Tan Y et al. The mammalian target of rapamycin pathway in the basolateral amygdala is critical for nicotine-induced behavioural sensitization. Int J Neuropsychopharmacol 2014; 17: 1881-1894.

145 McKee SA, Maciejewski PK, Falba T, Mazure CM. Sex differences in the effects of stressful life events on changes in smoking status. Addiction 2003; 98: 847-855.

146 Mantsch JR, Baker DA, Funk D, Le AD, Shaham Y. Stress-induced reinstatement of drug seeking: 20 years of progress. Neuropsychopharmacology 2016; 41: 335-356.

$147 \mathrm{Yu} \mathrm{G}$, Chen H, Sharp BM. Amplified reacquisition of nicotine self-administration in rats by repeated stress during abstinence. Psychopharmacology 2014; 231: 3189-3195.

$148 \mathrm{Yu} \mathrm{G}$, Sharp BM. Basolateral amygdala and ventral hippocampus in stressinduced amplification of nicotine self-administration during reacquisition in rat. Psychopharmacology 2015; 232: 2741-2749.

149 Beyler A, Namburi P, Glober GF, Simonnet C, Calhoon GG, Conyers GF et al. Divergent routing of positive and negative information from the amygdala during memory retrieval. Neuron 2016; 90: 348-361.

150 McKee SA, Sinha R, Weinberger AH, Sofuoglu M, Harrison EL, Lavery M et al. Stress decreases the ability to resist smoking and potentiates smoking intensity and reward. J Psychopharmacol 2011; 25: 490-502.

151 Dagher A, Tannenbaum B, Hayashi T, Pruessner JC, McBride D. An acute psychosocial stress enhances the neural response to smoking cues. Brain Res 2009; 1293: $40-48$

152 Jasinska AJ, Stein EA, Kaiser J, Naumer MJ, Yalachkov Y. Factors modulating neural reactivity to drug cues in addiction: a survey of human neuroimaging studies. Neurosci Biobehav Rev 2014; 38: 1-16.

153 Vollstädt-Klein S, Kobiella A, Buhler M, Graf C, Fehr C, Mann K et al. Severity of dependence modulates smokers' neuronal cue reactivity and cigarette craving elicited by tobacco advertisement. Addict Biol 2010; 16: 166-175.

154 Filbey FM, Sabbineni A, Hutchison KE. Identifying neurobiological phenotypes associated with alcohol use disorder severity. Neuropsychopharmacology 2011; 36: 2086-2096.

155 Koob GF. A role for brain stress systems in addiction. Neuron 2008; 59: 11-34.

156 Goudriaan AE, de Ruiter MB, van den Brink W, Oosterlaan J, Veltman DJ. Brain activation patterns associated with cue reactivity and craving in abstinent problem gamblers, heavy smokers and healthy controls: an fMRI study. Addict Biol 2010; 5: 491-503.

157 Feldstein Ewing SW, Filbey FM, Chandler LD, Hutchison KE. Exploring the relationship between depressive and anxiety symptoms and neuronal response to alcohol cues. Alcohol Clin Exp Res 2010; 34: 396-403.

This work is licensed under a Creative Commons AttributionNonCommercial-NoDerivs 4.0 International License. The images or ther third party material in this article are included in the article's Creative Commons license, unless indicated otherwise in the credit line; if the material is not included under the Creative Commons license, users will need to obtain permission from the license holder to reproduce the material. To view a copy of this license, visit http:// creativecommons.org/licenses/by-nc-nd/4.0/

(c) The Author(s) 2017 